\title{
SPECIFIC HEAT OF LIQUID AMMONIA
}

\author{
By Nathan S. Osborme and Milton S. Van Dusen
}

CONTENTS

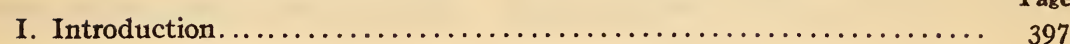

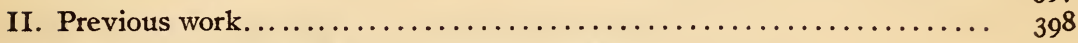

III. General description of apparatus and method ............... 399

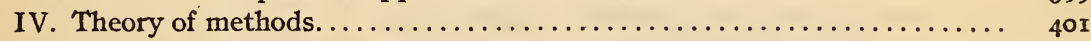

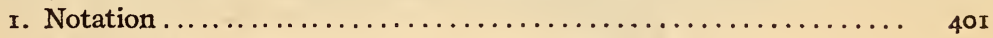

2. Determination of heat added...................... 402

3. Determination of specific heat of saturated liquid ......... 402

4. Determination of specific heat of liquid at constant pressure.... 403

5. Correlation of the two methods................... 406

V. Material.......................................... 408

VI. First method. Measurements under saturation conditions......... 409

I. Experimental details.......................... 409

2. Results of measurements...................... 410

VII. Second method. Measurements at constant pressure............ $4 \mathrm{I} 6$

I. Experimental details........................ 4I7

2. Results of measurements........................ $42 \mathrm{I}$

VIII. Form of empirical equation for specific heat of the saturated liquid.... $\quad 425$

IX. Conclusions. . . . . . . . . . . .

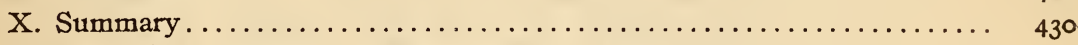

Appendix.-Tables of specific heat and heat content................. $43^{2}$

\section{INTRODUCTION}

In reviewing the existing data on the thermodynamic properties of ammonia, the dearth of calorimetric measurements is at once apparent. Only when it is remembered that calorimetric data are of primary importance in the computation of tables adapted to the needs of the engineer can the difficulties of the computer be appreciated. With regard to the specific heat of liquid ammonia it appears that the experimental difficulty of measurement and the absence of urgent need for accurate values have deterred all but a few from the attempt. More recently the progress in the production of artificial refrigeration has led to a need for more accurate tables than those existing, and the measurement of the specific heat of liquid ammonia, together with other thermodynamic properties, has been undertaken in response to the expressed wish of the refrigeration industries. 


\section{PREVIOUS WORK}

The previous determinations of specific heat of liquid ammonia are represented graphically in Fig. $\mathrm{I}$, together with the results of the present measurements. None of the previous measurements extend to temperatures below $0^{\circ} \mathrm{C}$.

Von Strombeck ${ }^{1}$ (1 890) used the method of mixtures. About $128 \mathrm{~g}$ of ammonia contained in a steel bomb were used in a calorimeter having a water equivalent of about $\mathrm{I} \mathrm{kg}$. The heat capacity from $+30^{\circ}$ to $+60^{\circ}$ was observed. Eight experiments were made.

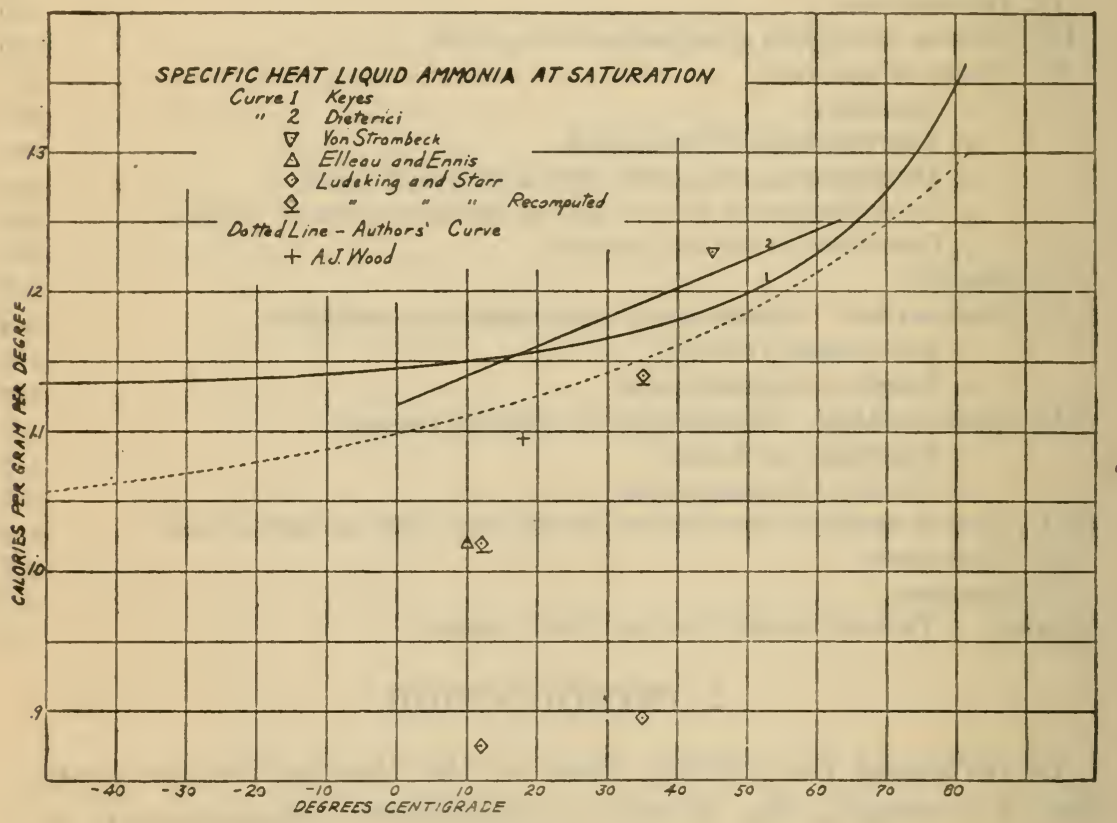

FIG. I

Ludeking and Starr ${ }^{2}$ ( 1893 ) employed a method similar to that of Von Strombeck but smaller apparatus. The total heat capacity of a steel shell of $16.12 \mathrm{~cm}^{3}$ capacity containing $10.01 \mathrm{~g}$ of ammonia was measured between $+46^{\circ} \mathrm{C}$ and $+26^{\circ} \mathrm{C}$. It appears from present knowledge of the specific volume of liquid ammonia that at temperatures above $13^{\circ} \mathrm{C}$ the liquid would have completely filled the container, and from the compressibility it may be estimated that at $46^{\circ}$, if the steel did not stretch considerably, the pressure within would have been in the neighborhood of 300 atmospheres. From the heat of compression of liquid ammonia 
it can be estimated that the heat capacity between $0^{\circ}$ and $24^{\circ}$ was approximately 15 per cent lower than it would have been under saturation conditions and that between $26^{\circ}$ and $46^{\circ}$ it was about $2 \mathrm{I}$ per cent lower. Both the published values and the values recomputed as indicated are shown in Fig. I.

Elleau and Ennis ${ }^{3}$ (1898) also used the method of mixtures between $0^{\circ}$ and $+25^{\circ}$. Nine grams of ammonia in a capsule of $20 \mathrm{~cm}^{3}$ capacity were used.

Dieterici and Drewes ${ }^{4}$ (I904) used the Bunsen ice calorimeter. The specimen of ammonia was inclosed in a sealed glass capsule of $\mathrm{I} .2 \mathrm{~cm}^{3}$ capacity.

A. J. Wood ${ }^{5}$ (I9I 2) used the method of mixtures with a sample of about $60 \mathrm{~g}$ of ammonia. Six experiments were made between $16^{\circ}$ and $20^{\circ} \mathrm{C}$.

Keyes and Brownlee ${ }^{6}$ (1916) have given an equation based upon unpublished experimental work of Babcock.

\section{GENERAL DESCRIPTION OF APPARATUS AND METHOD}

In carrying out the measurements of specific heat of the liquid two independent methods were used. In one method the heat added to a fixed amount confined in the calorimeter and the resulting change in temperature are measured under saturation conditions. By using independent data for the specific volumes of the two phases and for the latent heat of vaporization the corrections for the heat used to change the temperature and amount of vapor present may be determined and the specific heat of the saturated liquid obtained.

In the other method the calorimeter is kept full of liquid at a constant pressure above saturation, the heat added to the variable quantity, and the resulting change in temperature measured, due consideration being paid to the amount and temperature of the expelled portion. The result of this method of measurement is to give the specific heat of the liquid at a constant pressure.

By using the independent data for the latent heat of pressure variation of the liquid, the specific heat of the saturated liquid may be computed by general thermodynamic formulas, thus giving an independent check on the two methods of measurement.

${ }^{3}$ Jour. Franklin Inst., 145, pp. 189, $280,1898$.

Zeit. für die ges. Kalte Ind., 11, pp. 21, 47, 1904.

${ }^{5}$ Ice and Refrigeration, April, x912.

6 Thermodynamic Properties of Ammonia, John Wiley \& Son, 1916. (Since the foregoing went to press a description of the experimental determinations has appeared in Jour. Am. Chem. Soc., XXXIX, p. 1524; August, 1917.) 
The calorimeter used in making the experimental determinations having been previously described in detail elsewhere, ${ }^{7}$ only a brief description is here given. The instrument is of the aneroid type and was specially designed to meet the requirements of this investigation. A metal shell of sufficient strength is made in the form of a cylinder having a reentrant central tube. The interior annular space contains the material to be investigated. An electric heating coil and a resistance thermometer are located in the central tube. Heat developed in the coil is transmitted to the surrounding liquid, the distribution being favored by radial metal vanes. The interior of the shell is tinned and the outside nickeled. For preventing the transfer of unmeasured heat between this calorimeter and its environment it is suspended within a shield consisting of a thermally controlled jacket, with an air space between for thermal insulation. For evaluating the thermal leakage - that is, the heat exchanged with the surroundings by reason of temperature differences-multiple thermocouples with junctions distributed on the surfaces indicate temperature differences between calorimeter and jacket. Leakage is usually annulled by keeping the average jacket and calorimeter surface temperatures equal. The heat supplied to the calorimeter for producing temperature changes is developed at a nearly constant rate in the heating coil by current from a storage battery. Temperature changes are measured either by the resistance thermometer in the calorimeter or by an auxiliary resistance thermometer in the envelope, using thermocouples for the transfer. The energy supplied is determined by potentiometer measurements of current and potential drop and by the duration of the heating current, which is measured by the standard clock.

The material which is the subject of the measurement is introduced into the previously evacuated calorimeter through the tube provided for this purpose. The sample is confined in a special steel reservoir, which is closed by means of a valve. After being weighed the reservoir is suspended in an auxiliary thermoregulated bath and connected to the calorimeter. When the valves in this connection are open, the flow into the calorimeter is induced by vapor pressure difference caused by heating the reservoir above the temperature of the calorimeter. If the connecting tube is made to extend down to the bottom of the reservoir the transfer occurs by liquid flow, while if this tube terminates at the top of 
the reservoir the transfer occurs by distillation. The removal of the material from the calorimeter, except in the case of actual overflow by expansion when already full of liquid, is necessarily by distillation, since the orifices are at the top. The large amount of heat transferred when distilling to or from the calorimeter can be readily extracted or added by use of the cooling device or the heating coil as needed.

\section{THEORY OF METHODS}

\section{NOTATION}

$M=$ mass, in grams, of ammonia in the calorimeter.

$\theta=$ temperature, in centigrade degrees, of the thermodynamic scale.

$t=$ time.

$I=$ heating current in amperes (mean value).

$E=$ potential difference, in volts, across heating coil (mean value).

$Q=$ heat added in joules.

$N=$ heat capacity in joules per degree of calorimeter.

$V=$ volumetric capacity in $\mathrm{cm}^{3}$ of calorimeter.

$t^{\prime}=$ duration of heating current.

$t_{2}=$ duration of entire experiment.

$h=$ mean thermocouple indication, in millimeters of the galvanometer scale, during entire experiment.

$B=$ coefficient of "thermal leakage in joules per minute per millimeter galvanometer deflection.

$\theta_{1}, \theta_{2}=$ initial and final temperatures of calorimeter and contents when in equilibrium.

$\Delta \theta=\theta_{2}-\theta_{1}$.

$\theta_{m}=\frac{\theta_{2}+\theta_{1}}{2}$. The subscript $m$ will be used to refer to temperature $\theta_{m}$.

$C_{p}=$ specific heat at constant pressure $p$ and temperature $\theta$. $\sigma=$ specific heat, in joules per gram per degree, of the saturated liquid - that is, the liquid in equilibrium with the vapor.

$\sigma^{\prime}=$ specific heat, in joules per gram per degree, of the saturated vapor.

$u=$ specific volume in $\mathrm{cm}^{3} / g$ of the saturated liquid. $u^{\prime}=$ specific volume in $\mathrm{cm}^{3} / g$ of the saturated vapor. 
$L=$ latent heat of vaporization, in joules per gram, under saturation conditions.

$x=$ mass of vapor per gram total contents; i. e., dryness factor.

$I-x=$ mass of liquid per gram total contents.

$p=$ pressure.

$\pi=$ saturation pressure at temperature $\theta$.

$l=$ latent heat of pressure variation of liquid.

\section{DETERMINATION OF HEAT ADDED}

The heat supplied to the system composed of the calorimeter and the material which is the subject of measurement consists of two parts, namely, the heat developed in the electric heating coil and the heat transferred by thermal leakage. The latter is usually zero or small. This heat added is distributed in two parts, namely, that which is absorbed by the calorimeter and that absorbed by the contents. Using the symbols adopted, the above statement is expressed by the equation:

$$
\Delta Q+N \Delta \theta=I E t^{\prime}+B h t_{2}
$$

where $\Delta Q$ denotes the heat absorbed by the contents.

\section{DETERMINATION OF SPECIFIC HEAT OF SATURATED LIQUID}

The formula expressing the specific heat, $\sigma$, of the saturated liquid in terms of the measured quantity of heat added, $\Delta Q$; the observed change in temperature, $\Delta \theta$, from the initial to the final equilibrium condition; the total mass, $M$, present; the latent heat of vaporization, $L$; and the dryness factor, $x$, is obtained by the use of two thermodynamic relations for saturation conditions.

Disregarding as insignificant the thermal expansion of the calorimeter and consequent change in total volume of the contents, the amount of heat, $d Q$, required to produce a temperature change, $d \theta$, under saturation conditions, no external work being done, is given by the equation:

$$
\frac{d Q}{M}=(1-x) \sigma d \theta+x \sigma^{\prime} d \theta+L \frac{d x}{d \theta} d \theta
$$

Since $\sigma^{\prime}-\sigma=\frac{d L}{d \theta}-\frac{L}{\theta}$, by substituting and combining terms:

$$
\frac{d Q}{M}=\sigma d \theta-\frac{L x}{\theta} d \theta+\frac{d}{d \theta}(L x) d \theta
$$


Integrating between $\theta_{1}$ and $\theta_{2}$ and dividing by $\Delta \theta$

$$
\frac{\mathbf{I}}{M} \frac{\Delta Q}{\Delta \theta}=\frac{\mathrm{I}}{\Delta \theta} \int_{\theta_{1}}^{\theta_{2}} \sigma d \theta-\frac{\mathrm{I}}{\Delta \theta} \int_{\theta_{1}}^{\theta_{2}} \frac{L x}{\theta} d \theta+\frac{L_{2} x_{2}-L_{1} x_{1}}{\Delta \theta}
$$

For numerical computation of $\sigma$ this equation may be simplified if the variations of $\sigma$ and $\frac{L x}{\theta}$ with $\theta$ are such that over the temperature interval $\theta_{2}-\theta_{1}$ the following approximations may be made:

$$
\frac{\mathrm{I}}{\Delta \theta} \int_{\theta_{1}}^{\theta_{2}} \sigma d \theta=\sigma_{m}, \quad \frac{\mathrm{I}}{\Delta \theta} \int_{\theta_{1}}^{\theta_{2}} \frac{L x}{\theta} d \theta=\left(\frac{L x}{\theta}\right)_{m}
$$

where $\sigma_{m}$ denotes the value of $\sigma$ at the arithmetical mean temperature $\theta_{m}$ and $\left(\frac{L x}{\theta}\right)_{m}$ denotes the value of $\frac{L x}{\theta}$ at that same temperature.

Making these substitutions and solving for $\sigma_{m}$

$$
\sigma_{m}=\frac{\Delta Q_{I}}{\Delta \theta} \frac{L_{2} x_{2}-L_{1} x_{1}}{\Delta \theta}+\left(\frac{L x}{\theta}\right)_{m}
$$

The dryness factor, $x$, is given by the formula

$$
x=\frac{\frac{V}{M}-u}{u^{\prime}-u}
$$

\section{DETERMINATION OF SPECIFIC HEAT OF LIQUID AT CONSTANT PRESSURE}

In this method of measurement of specific heat, all the heat, $\Delta Q$, added to the contents of the calorimeter is used to produce a change in temperature of the liquid phase, but not all of the contents undergo the same change in temperature. Only that part which still remains in the calorimeter at the final equilibrium temperature passes through the entire temperature increment, that which flows out having a certain temperature, $\theta^{\prime}$, for each infinitesimal portion at the time when it emerges. This variable temperature, $\theta^{\prime}$, is observable by means provided in the instrument, and although not actually observed in each experiment its relation to the other variables can be established once for all.

The quantity of heat, $d Q$, added to the liquid in consequence of the change of temperature, $d \theta$, can be divided into two parts, the first the quantity required to produce the change, $d \theta$, in the entire 
amount, $M$, contained at any temperature, $\theta$, and second the quantity required to heat from $\theta$ to $\theta^{\prime}$ the amount, $d M$, expelled during the change, $d \theta$, thus

$$
d Q=M C_{p} d \theta+d M \int_{\theta}^{\theta^{\prime}} C_{p} d \theta
$$

where $\theta$ denotes the uniform temperature which the contents would ultimately attain if thermally isolated at constant pressure. This temperature may be called the effective mean temperature.

In order to get an expression for the total amount of heat, $\Delta Q$, added to the liquid during an experiment, $M, C_{p}$ and $\theta^{\prime}$ must be expressed in terms of $\theta$, so that equation (7) may be integrated.

Now the experiments show that $M$ and $C_{p}$ vary with the temperature in such manner that no significant error will be incurred within the range of temperature of any single experiment if they be expressed as linear functions of $\theta$, thus

$$
\begin{aligned}
M & =(M)_{m}\left[\mathrm{I}+b\left(\theta-\theta_{m}\right)\right] \\
C_{p} & =\left(C_{p}\right)_{m}\left[\mathrm{I}+a\left(\theta-\theta_{m}\right)\right]
\end{aligned}
$$

where $(M)_{m}$ and $\left(C_{p}\right)_{m}$ are the values of $M$ and $C_{p}$, respectively, at the mean temperature $\theta_{m}$, and $b$ and $a$ are constants. From the first of these equations it follows that

and from the second

$$
d M=(M)_{m} b d \theta
$$

$$
\int_{\theta}^{\theta^{\prime}} C_{p} d \theta=\left(C_{p}\right)_{m}\left(\theta^{\prime}-\theta\right)\left[\mathrm{I}-a \theta_{m}+\frac{a}{2}\left(\theta^{\prime}+\theta\right)\right]
$$

Making the foregoing approximations in equation (7) by substituting the four above relations, the equation becomes

$$
\begin{gathered}
d Q=(M)_{m}\left(C_{p}\right)_{m}\left\{\left[\mathrm{I}+a\left(\theta-\theta_{m}\right)\right]\left[\mathrm{I}+b\left(\theta-\theta_{m}\right)\right]\right. \\
\left.+b\left(\theta^{\prime}-\theta\right)\left[\mathrm{I}-a \theta_{m}+\frac{a}{2}\left(\theta^{\prime}+\theta\right)\right]\right\}
\end{gathered}
$$

For convenience of integration the equation may be rearranged and written in the form

$$
\begin{gathered}
d Q=(M)_{m}\left(C_{p}\right)_{m}\left[\left(\mathrm{I}-a \theta_{m}\right)\left(\mathrm{I}-b \theta_{m}\right)+a\left(\mathrm{I}-b \theta_{m}\right) \theta\right. \\
\left.+\frac{a b}{2} \theta^{2}+b\left(\mathrm{I}-a \theta_{m}\right) \theta^{\prime}+\frac{a b}{2} \theta^{\prime 2}\right] d \theta
\end{gathered}
$$


in which $(M)_{m},\left(C_{p}\right)_{m}, a, b$, and $\theta_{m}$ are constants, while $\theta^{\prime}$ is yet to be expressed in terms of $\theta$.

The relation between the temperature, $\theta^{\prime}$, at which the overflow leaves the calorimeter and the instantaneous effective mean temperature, $\theta$, of the liquid remaining behind was investigated by means of supplementary experiments, the details of which are described in another section. At the start of an experiment $\theta$ and $\theta^{\prime}$ are both equal to the initial temperature $\theta_{1}$. As the experiment proceeds and $\theta$ rises, $\theta^{\prime}$ also rises but less rapidly at first, so that it lags behind $\theta$. After a certain time, however, this lag becomes nearly constant, and during the remainder of the period of outflow $\theta^{\prime}$ is below $\theta$ by a nearly constant amount, which may be denoted by $\lambda$. Since the initial period is short and $\lambda$ is small, it is sufficiently accurate to write

$$
\begin{aligned}
& \theta^{\prime}=\theta_{1}, \text { for } \theta_{1} \overline{<} \theta=\theta_{1}+\lambda \\
& \theta^{\prime}=\theta-\lambda, \text { for } \theta_{1}+\lambda \overline{<} \theta \overline{<} \theta_{2}
\end{aligned}
$$

In integrating equation (9) from $\theta_{1}$ to $\theta_{2}$ it is therefore necessary to proceed with the terms which contain $\theta^{\prime}$ in two steps, the first from $\theta_{1}$ to $\theta_{1}+\lambda$ with $\theta^{\prime}=\theta_{1}$, and the second from $\theta_{1}+\lambda$ to $\theta_{2}$ with $\theta^{\prime}=\theta+\lambda$.

Accordingly the following expression is obtained for the whole quantity of heat, $\Delta Q$, added to the liquid during the experiment:

$$
\begin{aligned}
\Delta Q=(M)_{m}\left(C_{p}\right)_{m} & \left\{\int_{\theta_{1}}^{\theta_{2}}\left[\left(\mathrm{I}-a \theta_{m}\right)\left(\mathrm{I}+b \theta_{m}\right)+a\left(\mathrm{I}-b \theta_{m}\right) \theta+\frac{a b}{2} \theta^{2}\right] d \theta\right. \\
& +\int_{\theta_{1}}^{\theta_{1}+\lambda}\left[b\left(\mathrm{I}-a \theta_{m}\right) \theta_{1}+\frac{a b}{2} \theta_{1}{ }^{2}\right] d \theta \\
& \left.+\int_{\theta_{1}+\lambda}^{\theta_{2}}\left[b\left(\mathrm{I}-a \theta_{m}\right)(\theta-\lambda)+\frac{a b}{2}(\theta-\lambda)^{2}\right] d \theta\right\}
\end{aligned}
$$

If now for simplicity, $\theta_{1}$ be taken equal to zero, and the notation $\frac{\theta_{2}-\theta_{1}}{2}=\theta_{m}=\frac{1}{2} \Delta \theta$ be used, the result of carrying out the integrations in equation ( $\mathrm{IO}$ ) is to give the equation:

$$
\Delta Q=(M)_{m}\left(C_{p}\right)_{m} \Delta \theta\left[\mathrm{I}-b \lambda+\frac{a b \lambda}{4}+\frac{a b(\Delta \theta)^{2}}{\mathrm{I} 2}+\frac{b \lambda^{2}}{2 \Delta \theta}\left(\mathrm{I}-\frac{a \lambda}{3}\right)\right]
$$

The values of $a, b$, and $\lambda$ are, within the range of the present experiments, so small that when $\Delta \theta$ is $10^{\circ}$ the sum of the last three 
terms within the bracket does not exceed $0.000 \mathrm{I}$ of the bracketed expression, and these terms may, therefore, be ignored. The equation can be completely solved for $\left(C_{p}\right)_{m}$, but for the purpose of computing this quantity from the observed data it is put in the more convenient form

$$
\left(C_{p}\right)_{m}=\frac{\mathrm{I}}{(M)_{m}} \Delta Q-\frac{\mathrm{I}}{\Delta \theta}-\frac{\Delta M}{(M)_{m}}\left(C_{p}\right)_{m} \lambda
$$

The term $\frac{\mathrm{I}}{(M)_{m}} \frac{\Delta Q}{\Delta \theta}$ represents the heat added to the liquid per unit temperature change, per unit mass in calorimeter, when in equilibrium at the mean temperature of the experiment. It would equal the specific heat at the mean temperature if the experiment proceeded under ideal conditions such that the heat were instantaneously distributed uniformly throughout the liquid, making $\lambda=0$, for then the second term would vanish.

The term $\frac{\mathrm{I}}{(M)_{m}} \frac{\Delta M}{\Delta \theta}\left(C_{p}\right)_{m} \lambda$ represents the amount of heat per unit temperature change of contents, per unit mass of contents at the mean temperature of the experiment, required to change the temperature of the expelled portion from the effective mean temperature to the overflow temperature. It is, indeed, the correction to the preceding term for the departure of the actual experiment from the ideal process just described above.

\section{CORRELATION OF THE TWO METHODS}

Having the specific heat, $\sigma$, of the saturated liquid, determined by measurements made under saturation conditions, and the specific heat, $C_{p}$, at a constant pressure, $p$, above the saturation pressure for the highest temperature reached during the determination, the first step in the correlation of these results, for the purpose of an experimental check, is to compute the limiting value which $C_{p}$ approaches as $p$ approaches the saturation pressure, $\pi$, for the given temperature. For this computation a knowledge of the latent heat of pressure variation, $l$, is required over the range of temperature and pressure including the specific heat determinations.

By definition,

$$
\begin{gathered}
C_{p}=\left(\frac{\partial Q}{\partial \theta}\right)_{p} \\
l=\left(\frac{\partial Q}{\partial p}\right)_{\theta}
\end{gathered}
$$


since $\partial Q=\theta \partial \phi$ where $\phi$ is entropy,

$$
\begin{gathered}
C_{p}=\theta\left(\frac{\partial \phi}{\partial \theta}\right)_{p} \\
\frac{l}{\theta}=\left(\frac{\partial \phi}{\partial p}\right)_{\theta}
\end{gathered}
$$

differentiating the first of these identities with respect to $p$ and the second with respect to $\theta$

$$
\begin{aligned}
& \frac{\partial}{\partial p}\left(C_{p}\right)=\theta \frac{\partial^{2} \phi}{\partial \theta \partial p} \\
& \frac{\partial}{\partial \theta}\left(\frac{l}{\theta}\right)_{p}=\frac{\partial^{2} \phi}{\partial \theta \partial p}
\end{aligned}
$$

hence it follows that

$$
\frac{\partial}{\partial p}\left(C_{p}\right)=\theta \frac{\partial}{\partial \theta}\left(\frac{l}{\theta}\right)_{p}
$$

The change in $C_{p}$ for a change in pressure from the observed pressure, $p$, to the saturation pressure, $\pi$, at the same temperature, $\theta$, is obtained by integrating equation ( 13 ) over this pressure interval. Examination of the experimental data for $l$ showed that within the range of temperature and pressure employed in the experiments the quantity $\frac{\partial}{\partial \theta}\left(\frac{l}{\theta}\right)$ may be treated as independent of $p$ in this integration without introducing any significant error. Therefore, since $\theta$ also is constant during this integration, the following equation is obtained for the change in $\mathrm{C}_{p}$ :

$$
\left[C_{p}\right]_{\theta, \pi}-\left[C_{p}\right]_{\theta, p}=\theta \frac{\partial}{\partial \theta}\left(\frac{l}{\theta}\right)(\pi-p)
$$

by means of which the values of $\left[C_{p}\right]_{\theta, \pi}$ may be computed from the data for $C_{p}$ and $l$.

The next step is to compute the specific heat, $\sigma$, of the saturated liquid from these limiting values of $\left[C_{p}\right]_{\theta, \pi}$ just found.

Starting with the general equation

$$
d Q=C_{p} d \theta+l d p
$$

which is true for any simultaneous variations of $p$ and $\theta$ during which the fluid remains homogeneous, it follows that

$$
\frac{d Q}{d \theta}=C_{p}+l \frac{d p}{d \theta}
$$


If the change be restricted to saturation conditions, then by definition $\frac{d Q}{d \theta} \equiv \sigma$ and $\frac{d p}{d \theta} \equiv \frac{d \pi}{d \theta}$,

whence

$$
\sigma=\left[C_{p}\right]_{\theta_{1} \pi}+[l]_{\theta_{\pi} \pi} \frac{d \pi}{d \theta} .
$$

The values of $\sigma$ obtained indirectly by the foregoing method of computation from observed values of $C_{p}$ and $l$ should, of course, agree with those obtained by the method of measurement under actual conditions of saturation, and the comparison of the two series of values affords a valuable test of accuracy.

\section{MATERIAL}

The material used in these determinations was prepared by Messrs. McKelvy and Taylor of the chemical division of this Bureau by methods described in detail in an independent paper. ${ }^{8}$ A brief description of the process of preparation is here given.

A sample of commercial ammonia was transferred by distillation into a steel container which would hold about a kilogram. From this it was again transferred by distillation into a similar vessel containing metallic sodium, to remove any remaining traces of water. Following this dehydration, the purification was continued by from six to eight consecutive fractional distillations, the first and last tenths of each distillation being rejected. Removal of the rejected first fractions was performed in such a way as to extract the noncondensing gas present.

Two samples purified in the above manner, designated $\mathrm{A}$ and $\mathrm{C}$, were used in the determination.

Sample A, prepared March, I916, and used in the determinations by the first method, was made from commercial anhydrous ammonia manufactured from ammonium sulphate.

Tests showed the following impurities in this sample: Noncondensing gases in the vapor phase at $25^{\circ} \mathrm{C}$, 1 part in 10000 by volume; water, I part in 10 ooo by weight.

Sample C, prepared July, I9I6, and used in the determinations by the second method, was made from commercial anhydrous ammonia manufactured by the synthetic method. The sample showed about the same proportion of noncondensing gases as sample A. 


\section{FIRST METHOD. MEASUREMENTS UNDER SATURA- TION CONDITIONS}

In the determinations by this method the ammonia contained in the calorimeter is part liquid and part vapor, and, therefore, the pressure is that of saturated vapor, and the state and relative amount of each phase when in equilibrium are completely defined by the temperature. The observations yield, as a direct result, the heat added to the contained ammonia per degree temperature rise. For the obvious purpose of minimizing the variation with temperature of the heat content of the vapor present, only enough vapor space is allowed when filling to insure a safe margin at all temperatures to be experienced. From the measured heat capacity of the total contents the specific heat of the liquid may be computed, if the specific volumes of the two phases and the latent heat of vaporization which determine the correction for change in heat content of the vapor are known.

\section{EXPERIMENTAL DETAILS}

The sample was introduced into the calorimeter and the amount determined by difference between the initial and final weights of the reservoir. Each filling served for a series of experiments. The heat capacity of the filled calorimeter was determined over suitable temperature intervals throughout the range to be covered. The heat capacity of the empty calorimeter was determined by independent experiments. Briefly stated, the manipulations and observations during an experiment occurred as follows:

The calorimeter containing the sample was cooled by means of the special cooling device to the initial temperature of the first experiment of a series. The jacket was brought under control of the thermoregulator at the temperature of the calorimeter. The initial temperature of the calorimeter was determined by observing the resistance of one or both the platinum thermometers. Electric current was then passed through the heating coil of the calorimeter for a measured interval of time. During this time alternate readings of current and potential drop were made periodically to determine the rate of energy supply to the calorimeter. Meanwhile, by hand control of the jacket-heating current, the temperature of the jacket surface was kept nearly equal to the rising temperature of the calorimeter surface, the deviations being observed by means of the thermocouples, and the sum of the deviations during an experiment usually being made zero. 
After the interruption of the heating current the jacket was again brought under control of the thermoregulator, and when the calorimeter attained thermal equilibrium the thermometer resistance was again observed to determine the final temperature. This was usually taken as the initial temperature of the succeeding experiment, and the process repeated until completion of the series.

A complete description of the method and the results of the calibration of the calorimeter resistance thermometer and of the determinations of the heat capacity of the calorimeter is given in a preceding paper. ${ }^{9}$

\section{RESULTS OF MEASUREMENTS}

The experimental data ${ }^{10}$ obtained from the observations made by the first method, together with the computations for obtaining the specific heat, $\sigma$, of the saturated liquid, are given in Tables I and 2. The computations are made following the method described in Section IV.

9 This Bulletin, 14, p 133; 1917.

10 The laboratory scale of temperature actually used in the measurements given in this paper is the scale of a resistance thermometer of Heraeus platinum of highest purity according to the equation:

$$
\theta=\frac{R_{\theta}-R_{0}}{R_{100}-R_{0}} 100+\delta\left(\frac{\theta}{100}-1\right) \frac{\theta}{100}
$$

$R_{0}$ and $R_{100}$ are the resistances of the thermometer at the temperatures, under normal atmospheric pressure, of melting ice and saturated steam, respectively, and $\delta$ is determined by substituting for $R_{\theta}$ in the above equation the resistance of the thermometer at the temperature of sulphur vapor under normal atmospheric pressure, and 444.6 for $\theta$. The value of $\delta$ for the calorimeter thermometer was found by comparison with a standardized thermometer to be 1.48 . The departure of the scale so defined from the "thermodynamic" or "ideal gas" scale down to $-50^{\circ} \mathrm{C}$ is not more than the limit of accuracy of existing gas-thermometer data.

For all mathematical relations involving the second law of thermodynamics the temperatures are necessarily referred to the absolute zero. In recording laboratory data numerically it is usually convenient to use the ice point as zero. Sometimes in the mathematical analyses where differences only are involved it is convenient to simplify the algebra by choosing an arbitrary zero for a particular case. In the numerical tables of data and reductions no ambiguity arises on this account, as the experiments were conducted between $-50^{\circ}$ and $+50^{\circ}$ from the ice point, so that the recorded temperatures never numerically exceed $50^{\circ}$ while the absolute temperatures are never less than $200^{\circ}$.

Where numerical values are given, the joule used in this paper is determined by the relation $\frac{Q}{t}=\frac{E^{2}}{R}$, where $Q$ is the number of joules transformed into heat in a given ele ctric circuit in $t$ seconds, $E$ the number of volts potential drop, and $R$ the number of ohms resistance; taking I volt $=\frac{I}{1.01830} \times e m f$ of mean Weston normal cell at $20^{\circ} \mathrm{C}$, and I ohm $=$ resistance at $0^{\circ} \mathrm{C}$ of $106.300 \mathrm{~cm}$ of uniform merc ury column $14.4521 \mathrm{~g}$ in mass. The difference between the international joule, realized thus, and the absolute joule is, according to present evidence, perhaps I part in 3000 . (B. S. Circular No. 60, rst ed., p. 56; 1916.) The ampere is used only as an intermediary unit, being determined by the relation $I=\frac{E}{R}$ where $I=$ number of amperes. 


\begin{tabular}{|c|c|}
\hline 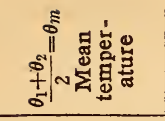 & 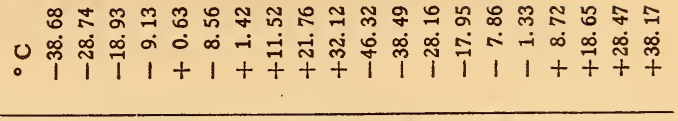 \\
\hline 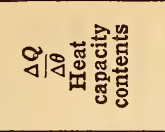 & 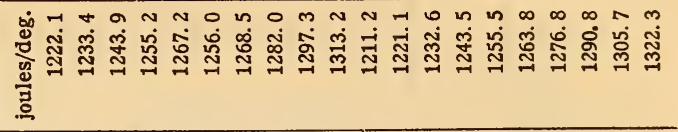 \\
\hline 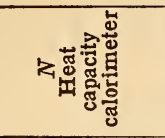 & 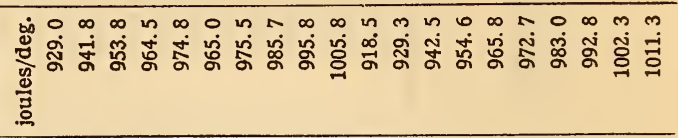 \\
\hline 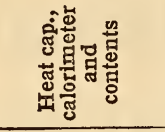 & 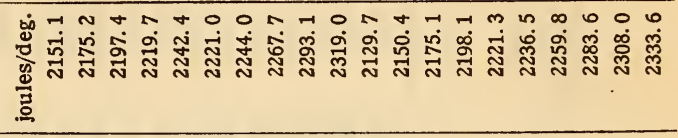 \\
\hline 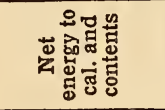 & 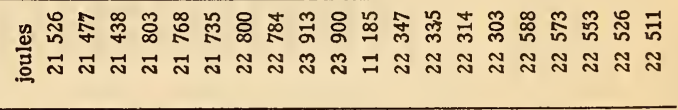 \\
\hline 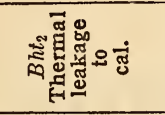 & 00000000000000000000 \\
\hline 总 & 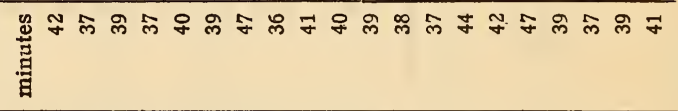 \\
\hline 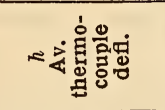 & 昌 00000000000000000000 \\
\hline 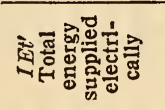 & 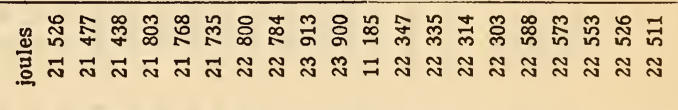 \\
\hline 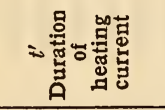 & 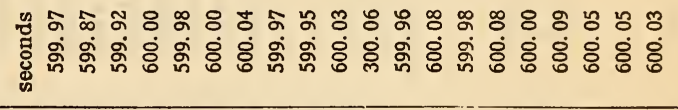 \\
\hline 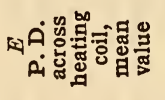 & 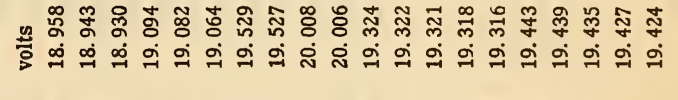 \\
\hline 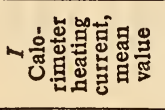 & 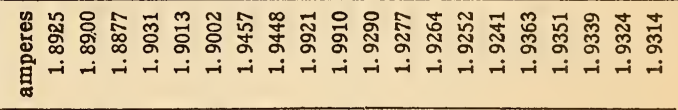 \\
\hline 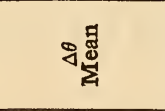 & 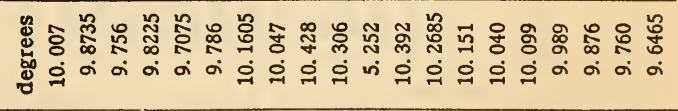 \\
\hline 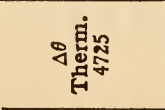 & 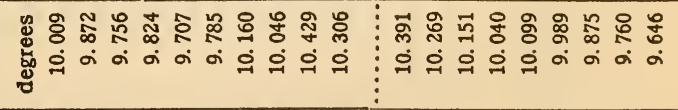 \\
\hline 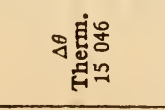 & 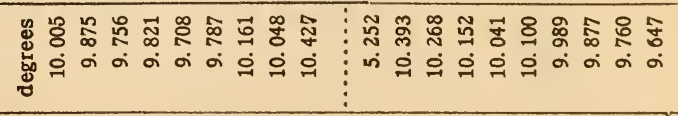 \\
\hline 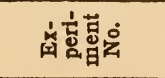 & 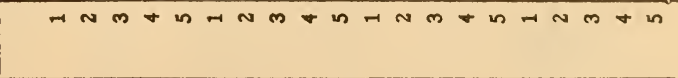 \\
\hline ค̆ & 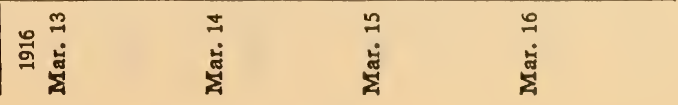 \\
\hline
\end{tabular}




\begin{tabular}{|c|c|c|}
\hline & 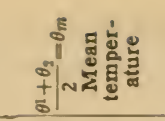 & 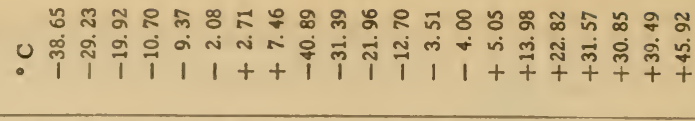 \\
\hline & 웡ㅇㄱ & 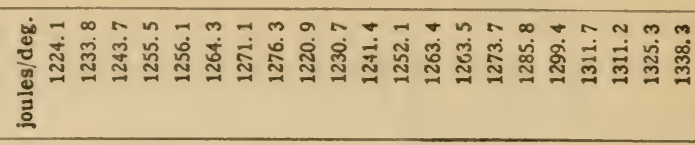 \\
\hline & $\mathrm{z}$ & 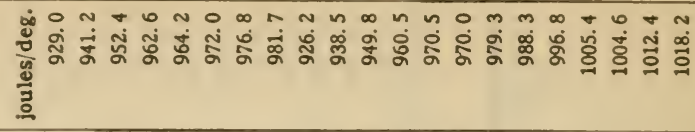 \\
\hline & 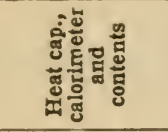 & 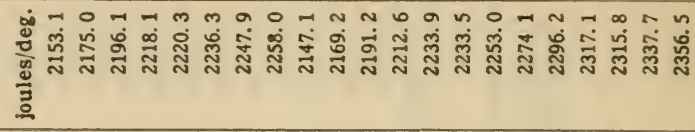 \\
\hline$\sum_{z}^{n}$ & 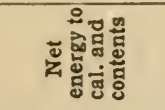 & 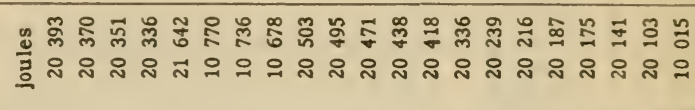 \\
\hline 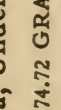 & 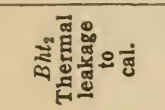 & 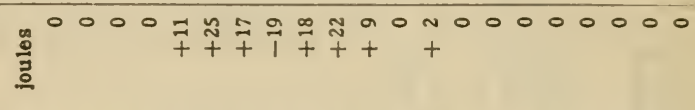 \\
\hline 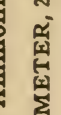 & مُ & 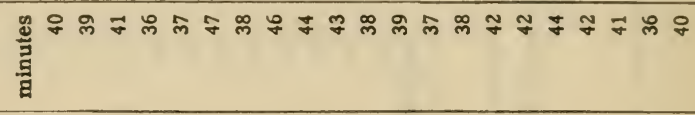 \\
\hline 仓ુ & 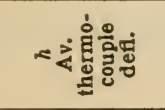 & 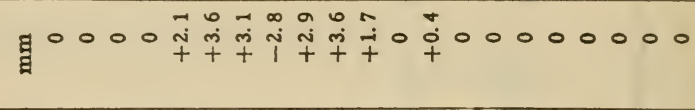 \\
\hline 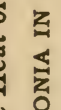 & 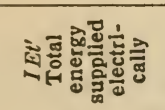 & 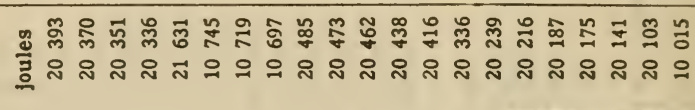 \\
\hline $\begin{array}{l}\sum_{4} \\
\qquad \\
0\end{array}$ & 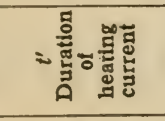 & 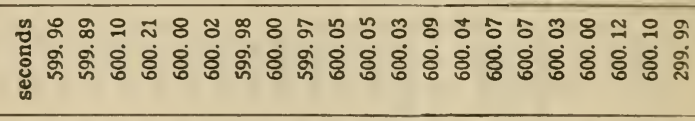 \\
\hline$\underset{\substack{1 \\
i \\
t}}{\substack{1 \\
t}}$ & 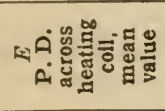 & 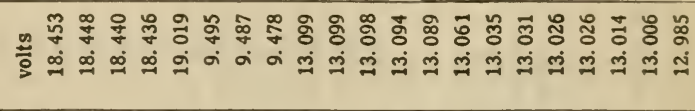 \\
\hline$\frac{d}{4}$ & 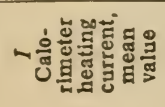 & 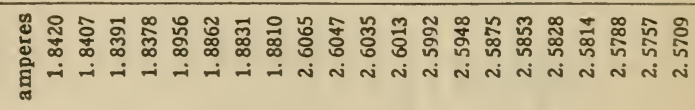 \\
\hline & ४ 距 & 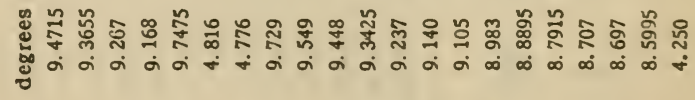 \\
\hline & ๑鬼产 & 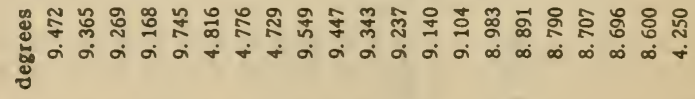 \\
\hline & 良兑 & 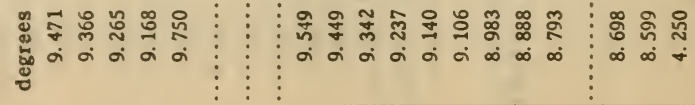 \\
\hline & 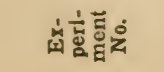 & 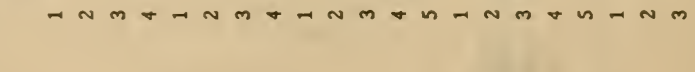 \\
\hline & ด̆ & 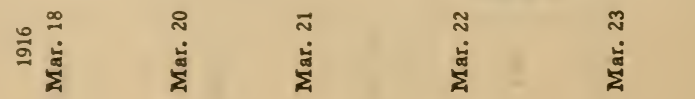 \\
\hline
\end{tabular}


TABLE 2.-First Method-Corrections for Vapor

$$
\sigma=\frac{1}{M} \frac{\Delta Q}{\Delta \theta}-\frac{L_{2} x_{2}-L_{1} x_{1}}{\Delta \theta}+\left[\frac{L x}{\theta}\right]_{m}
$$

PART

\begin{tabular}{|c|c|c|c|c|c|c|}
\hline \multirow{2}{*}{$\begin{array}{l}\text { Heat cap. } \\
\text { contents } \\
\text { from } \\
\text { Table } 1 \\
\frac{1}{M} \frac{\Delta Q}{\Delta \theta}\end{array}$} & \multicolumn{2}{|c|}{$\begin{array}{l}\text { Correction terms } \\
\text { for vapor }\end{array}$} & \multirow{2}{*}{$\begin{array}{c}\text { Specific } \\
\text { heat of } \\
\text { liquid } \\
\sigma_{\text {obs. }}\end{array}$} & \multirow{2}{*}{$\begin{array}{c}\text { Calc. from } \\
\text { empirical } \\
\text { equation } \mathrm{A} \\
\sigma_{\text {calc. }}\end{array}$} & \multirow{2}{*}{$\begin{array}{l}\text { Obs.- } \\
\text { Calc. }\end{array}$} & \multirow{2}{*}{$\begin{array}{c}\text { IVean } \\
\text { temp. } \\
\text { from } \\
\text { Table } 1 \\
\theta_{m}\end{array}$} \\
\hline & $\frac{L_{2} x_{2}-L_{1} x_{1}}{\Delta \theta}$ & {$\left[\frac{L x}{\theta}\right]_{m}$} & & & & \\
\hline J/g.deg. & J/g.deg & J/g.deg. & J/g.deg. & J/g.deg. & J/g.deg. & ${ }^{\circ} \mathrm{C}$ \\
\hline 4.455 & +0.016 & +0.002 & 4.441 & 4.441 & \pm 0.000 & -38.68 \\
\hline 4. 496 & .018 & .002 & 4.480 & 4.474 & +.006 & -28.74 \\
\hline 4. 534 & .022 & .003 & 4.515 & 4. 511 & +.004 & -18.93 \\
\hline 4.576 & .023 & .004 & 4. 557 & 4.553 & +.004 & -9.13 \\
\hline 4. 620 & .023 & .004 & 4. 601 & 4.599 & +.002 & +.63 \\
\hline 4.578 & .023 & .004 & 4. 559 & 4.554 & +.005 & -8.56 \\
\hline 4. 624 & .023 & .004 & 4.605 & 4.603 & +.002 & +1.42 \\
\hline 4. 673 & .021 & .005 & 4.657 & 4.657 & \pm .000 & +11.52 \\
\hline 4.729 & .009 & .005 & 4.725 & 4.723 & +.002 & +21.76 \\
\hline 4. 787 & -.010 & .005 & 4.802 & 4.798 & +.004 & +32.12 \\
\hline 4.415 & +.011 & .001 & 4.405 & 4. 417 & -.012 & -46.32 \\
\hline 4. 451 & .016 & .002 & 4. 437 & 4.441 & -.004 & -38.49 \\
\hline 4.493 & $.01,9$ & .002 & 4.476 & 4.476 & \pm .000 & -28.16 \\
\hline 4.533 & .021 & .003 & 4.515 & 4.514 & +.001 & -17.95 \\
\hline 4.577 & .024 & .004 & 4. 557 & 4.558 & -.001 & -7.86 \\
\hline 4.607 & .023 & .004 & 4.588 & 4.590 & -.002 & -1.33 \\
\hline 4. 654 & .021 & .005 & 4.638 & 4. 642 & -.004 & +8.72 \\
\hline 4.705 & .014 & .005 & 4. 696 & 4. 703 & -.007 & +18.65 \\
\hline 4.760 & -.003 & .005 & 4.768 & 4.769 & -.001 & +28.47 \\
\hline 4.820 & -.023 & .005 & 4. 848 & 4.848 & \pm .000 & +38.17 \\
\hline
\end{tabular}

PART 2

\begin{tabular}{|r|r|r|r|r|r|r|}
\hline 4.456 & +0.016 & +0.002 & 4.442 & 4.441 & +0.001 & -38.65 \\
4.491 & .017 & .002 & 4.476 & 4.473 & +.003 & -29.23 \\
4.527 & .021 & .003 & 4.509 & 4.507 & +.002 & -19.92 \\
4.570 & .023 & .004 & 4.551 & 4.546 & +.005 & -10.70 \\
4.572 & .023 & .004 & 4.553 & 4.552 & +.001 & -9.37 \\
4.602 & .023 & .004 & 4.583 & 4.585 & -.002 & -2.08 \\
4.627 & .023 & .004 & 4.608 & 4.610 & -.002 & +2.71 \\
4.646 & .021 & .005 & 4.630 & 4.635 & -.005 & +7.46 \\
4.444 & .014 & .001 & 4.431 & 4.433 & -.002 & -40.89 \\
4.480 & .017 & .002 & 4.465 & 4.465 & \pm .000 & -31.39 \\
4.519 & .021 & .003 & 4.501 & 4.499 & -.002 & -21.96 \\
4.558 & .022 & .003 & 4.539 & 4.537 & +.002 & -12.70 \\
4.599 & .023 & .004 & 4.580 & 4.579 & +.001 & -3.51 \\
4.599 & .023 & .004 & 4.580 & 4.577 & +.003 & -4.00 \\
4.636 & .022 & .004 & 4.618 & 4.622 & -.004 & +5.05 \\
4.680 & .019 & .005 & 4.666 & 4.673 & -.007 & +13.98 \\
4.730 & .007 & .005 & 4.728 & 4.729 & -.001 & +22.82 \\
4.775 & -.010 & .005 & 4.790 & 4.793 & -.003 & +31.57 \\
4.773 & -.008 & .005 & 4.786 & 4.787 & -.001 & +30.85 \\
4.824 & -.029 & .005 & 4.858 & 4.860 & +.002 & +39.49 \\
4.872 & -.050 & .004 & 4.926 & 4.921 & +.005 & +45.92 \\
& & & & & & \\
\hline
\end{tabular}


The approximations involved in the application of this method to the data here reduced result in no error in $\sigma_{\mathrm{m}}$ greater than I part in 5000 .

The calculation of $L x$ and $\frac{L x}{\theta}$ is given in Table 3 , the following formula being used, together with the values of $L$ and $\theta$.

$$
x=\frac{\frac{V}{M}-u}{u^{\prime}-u}
$$

TABLE 3.-First Method-Calculation of Corrections for Vapor

PART 1.-FIRST FILLING, 274.33 GRAMS

\begin{tabular}{|c|c|c|c|c|c|c|c|c|c|c|}
\hline $\begin{array}{c}\text { Tempera- } \\
\text { ture } \\
\theta\end{array}$ & $\begin{array}{c}\text { Total } \\
\text { volume } \\
\text { in } \\
\text { calorim- } \\
\text { eter } \\
V\end{array}$ & $\begin{array}{c}\text { Mean } \\
\text { specific } \\
\text { volume } \\
\text { of } \\
\text { contents } \\
\frac{V}{M}\end{array}$ & 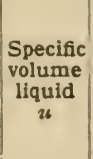 & $\begin{array}{c}\text { Specific } \\
\text { volume } \\
\text { vapor } \\
u^{\prime}\end{array}$ & $\frac{V}{M}-u$ & $u^{\prime}-u$ & $\begin{array}{c}\text { Fraction } \\
\text { which is } \\
\text { vapor } \\
x=\frac{\frac{V}{M}-u}{u^{\prime}-u}\end{array}$ & $\begin{array}{c}\text { Latent } \\
\text { heat of } \\
\text { vaporiza- } \\
\text { tion } \\
\text { tentative } \\
\text { value } \\
L\end{array}$ & $L_{x}$ & $\frac{L_{x}}{\theta}$ \\
\hline${ }^{\circ} \mathrm{C}$ & $\mathrm{cm}^{2}$ & $\mathrm{~cm}^{3 / 8}$ & $\mathrm{~cm}^{3} / \mathrm{g}$ & $\mathrm{cm}^{3} / \mathrm{g}$ & $\mathrm{cm}^{3} / \mathrm{g}$ & $\mathrm{cm}^{3} / \mathrm{g}$ & & joules/g & joules/g & joules $/ \mathrm{g}$ \\
\hline-50 & 500.8 & 1.8256 & 1.4241 & 2550 & 0.4015 & 2549 & 0.000158 & 1416 & 0.223 & 0.0010 \\
\hline-40 & 501.0 & 1.8263 & 1.4489 & 1514 & .3774 & 1513 & .000250 & 1388 & .346 & .0015 \\
\hline-30 & 501.2 & 1.8270 & 1.4754 & 941 & .3516 & 940 & .000374 & 1360 & .509 & .0021 \\
\hline-20 & 501.4 & 1.8277 & 1.5033 & 612 & .3244 & 611 & .000531 & 1329 & .706 & .0028 \\
\hline-10 & 501.6 & 1.8285 & 1.5332 & $414 \cdot 0$ & .2953 & 412.5 & .000716 & 1297 & .929 & .0035 \\
\hline 0 & 501.8 & 1.8291 & 1. 5658 & 288.7 & .2633 & 287.1 & .000917 & 1263 & 1.159 & .0042 \\
\hline 10 & 502.0 & 1.8299 & 1.6006 & 205.0 & .2293 & 203.4 & .001127 & 1228 & 1. 384 & .0049 \\
\hline 20 & 502.2 & 1.8306 & 1.6381 & 148.0 & .1925 & 146.4 & .001315 & 1190 & 1.564 & .0053 \\
\hline 30 & 502.4 & 1.8313 & 1.6793 & 110.2 & .1520 & 108.5 & .001401 & 1147 & 1.608 & .0053 \\
\hline 40 & 502.6 & 1.8320 & 1.7251 & 82.8 & .1069 & 81.1 & .001319 & 1101 & 1.452 & .0046 \\
\hline 50 & 502.8 & 1.8327 & 1.7760 & 63.0 & .0567 & 61.2 & .000926 & 1053 & .975 & .0030 \\
\hline
\end{tabular}

PART 2.-SECOND FILLING, 274.72 GRAMS

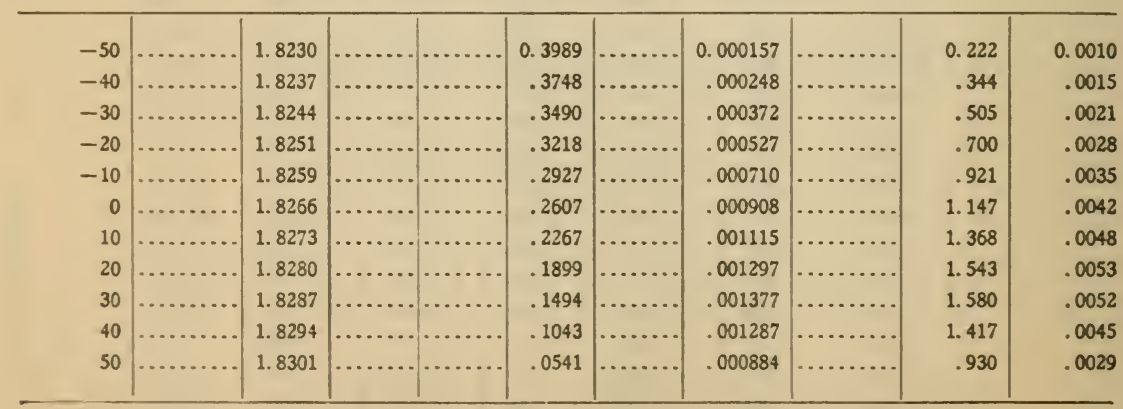


The values of $x$ for the two fillings are shown graphically as functions of $\theta$ in Fig. 2.

The values of $\frac{L_{2} x_{2}-L_{1} x_{1}}{\Delta \theta}$ and $\left(\frac{L x}{\theta}\right)_{\mathrm{m}}$ used in the calculations of Table 2 were interpolated graphically from Table 3 .

The volume, $V$, of the calorimeter was determined before the calorimeter was assembled, by weighing empty and again filled with water at a known temperature. The variation in volume with temperature need not be known accurately. It was obtained from

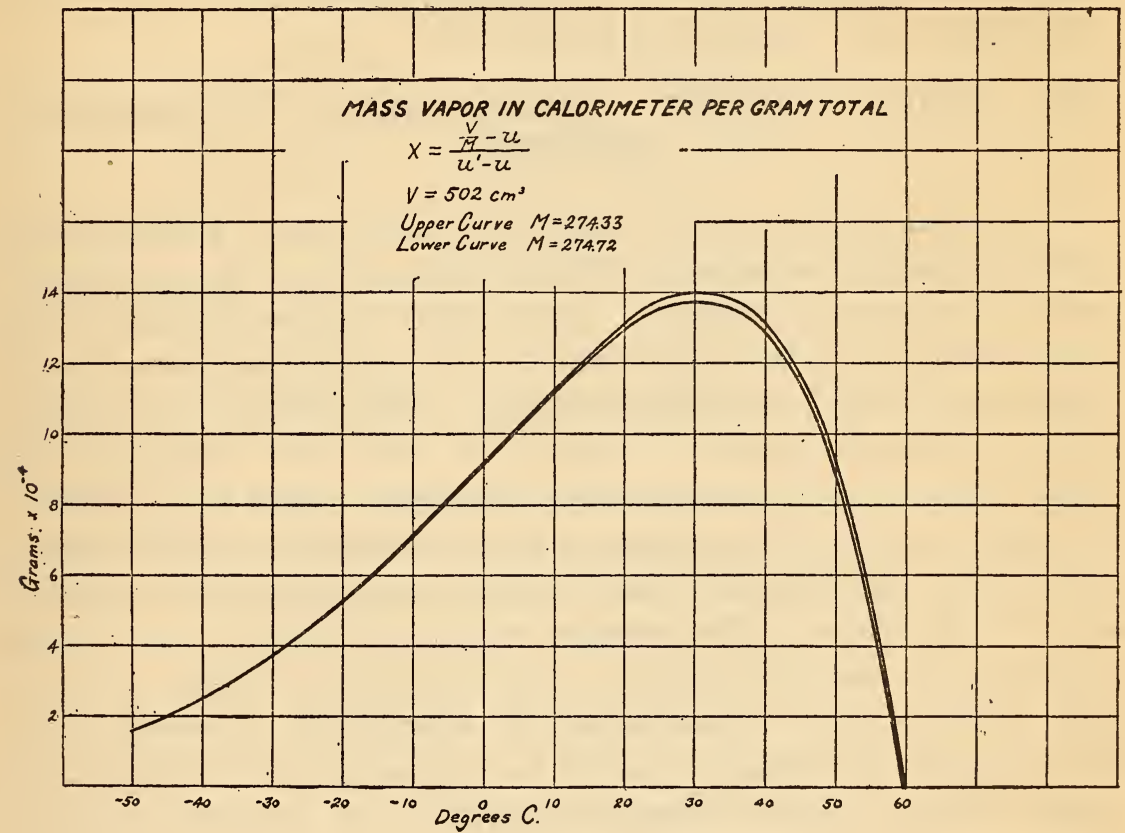

FIG. 2

independent determinations of the change in amount of liquid ammonia contained at various temperatures and pressures.

The values for the specific volumes of ammonia liquid and vapor are preliminary values from the measurements made at this Bureau by Harper, Cragoe, and O'Connor, the final results of which will be published in a separate paper.

The values of the latent heat of vaporization are from data published under a separate title. ${ }^{11}$

11 Osborne and Van Dusen, Latent Heat of Vaporization of Ammonia. This Bulletin, 14; 19r7. 
The results of the foregoing direct measurements of the specific heat of liquid ammonia under saturation conditions may be represented by the empirical equation

$$
\sigma=3.0931-0.00064 \theta+\frac{17.329}{\sqrt{133-\theta}}
$$

in which $133^{\circ}$ is taken as the temperature at the critical point. The form of this equation is discussed in Section VIII. A comparison between the observed values and those calculated by this equation is given in Table 2. The possible sources of error in the first method are discussed in Section IX.

\section{SECOND NETHOD-MEASUREMENT AT CONSTANT PRESSURE}

The primary object of this series of measurements was to afford a check upon the accuracy of the previous series of measurements under saturation conditions. In the first method distillation in the connecting tubes might occur, thus introducing an error ${ }^{12}$ which could not be readily evaluated. The method of measurement at constant pressure, however, in which the tubes are kept filled with liquid, eliminates this possibility. The two methods are fundamentally independent. In the first method a fixed mass of material consisting of both liquid and vapor phases is confined in the calorimeter. The relative amounts of these two phases depend upon the temperature, and corrections involving a knowledge of the specific volumes and the latent heat of vaporization are, therefore, necessary. In the second method the liquid phase alone entirely fills the calorimeter space, and, since the thermal expansion of the material differs from that of the calorimeter itself, the amount contained varies with the temperature. It was scarcely anticipated when the second method was undertaken that it would yield results comparable in precision with the first method, on account of greater experimental difficulty, although it was expected to disclose any serious error in the first method due to distillation in the connecting tubes. As eventually carried out, however, this method gave a precision equal to that of the first, and the possible sources of systematic error, while different from those in the first method, appeared no greater.

\footnotetext{
12 It is estimated that the maximum error due to this cause could not have exceeded I part in rooo, and that the average error was much less than this, but the comparison between the results of the two methods furnishes the most convincing evidence as to its limit.
} 


\section{EXPERIMENTAL DETAILS}

In filling the calorimeter, the reservoir used to hold the sample was provided with a tube reaching to the bottom, so that the transfer occurred by liquid flow induced by differences of vapor pressures inside the calorimeter and in the reservoir. By keeping the reservoir somewhat warmer than the calorimeter, the latter could always be kept full of liquid when the valves in the connecting tube were open, provided, of course, sufficient material were present to more than fill the calorimeter at all temperatures. In making a determination the reservoir was kept at a constant temperature by means of the thermoregulator. This temperature was observed, and it furnished, when supplemented with data for vapor pressure of ammonia at various temperatures, a means of determining the pressure, which for this purpose need not be known with great exactness. Thus, the pressure in the calorimeter remained constant, whereas the mass contained varied with the temperature. The manner of measurement of the heat added to the calorimeter and the initial and final equilibrium temperatures was identical with that already described under the first method.

The mass of liquid contained in the calorimeter at various temperatures and pressures was determined by a separate series of experiments. By keeping a fixed total mass in calorimeter and reservoir the variation in mass contained in the calorimeter was found by making weighings of the reservoir, closed off and detached from the calorimeter when the latter was in equilibrium. The total amount contained in the calorimeter when full at a single temperature and pressure was determined, as in the first method, by emptying.

It is shown (Sec. IV , 4; p. 403) where the theory of this method is discussed that the computation of the specific heat from the observed quantities can be made with sufficient accuracy, by means of a very simple formula, if the relation between the temperature, $\theta^{\prime}$, of the outflow and the instantaneous temperature, $\theta$, of the contents has the characteristics of an ordinary case of lag. The survey of these temperatures, by which "this relation was established, was made the object of the series of supplementary experiments, which are now to be described. In each of these experiments the operations were the same as in a specific heat measurement, with the exception that the usual calorimetric observations were omitted and, instead, the two temperatures $\theta$ 
and $\theta^{\prime}$ were each observed periodically. The place of departure of the liquid from the calorimeter was taken as the section of the outflow tube midway between the calorimeter and the jacket. The exactness of this location is not of great importance. To obtain the temperature $\theta^{\prime}$ of the liquid at this place, the auxiliary thermocouples, with junctions on the outflow tubes and calorimeter top, were used. These couples were part of the permanent equipment of the calorimeter and have been described in connection therewith. The reference junction was located on the jacket. The temperature of the jacket was obtained periodically by observing the resistance of the platinum thermometer in the envelope and simultaneously observing, by means of the surface thermocouples, the difference in temperature between this thermometer and the jacket. A record was thus obtained with respect to time of the temperatures of three points in close proximity to the outflowing liquid, namely, the calorimeter top and the two points on the outflow tube one-fourth and three-fourths the distance along the tube from the calorimeter to the jacket and designated respectively $A, B$, and $C$.

To obtain a value for the temperature $\theta$, the obvious method of observing the overflow of the liquid itself was employed. For this purpose a vertical glass tube closed at the top, graduated to tenths of cubic centimeters and surrounded by a stirred oil bath thermally controlled, was attached by a small tube, terminated by a valve, to the outlet provided for the manometer connection. This graduated tube constituted the isothermal stem of a thermometer, the bulb of which was the calorimeter itself, the two being connected by a tube of small volume. The fact that the stem was less than a centimeter in diameter made the thermometer sensitive to o:or $\mathrm{C}$ with ammonia as the liquid, since the volume of the bulb was about $500 \mathrm{~cm}^{3}$. The volume of the stem was sufficient to accommodate the expansion of the ammonia in any experiment covering a range of 10 degrees. This dilatometric thermometer was calibrated in place directly in terms of the equilibrium temperature of the calorimeter as a part of each experiment and for the conditions then existing, and except for corrections far within the precision of the readings ${ }^{13}$ it indicated the instantaneous temperature of the liquid contained in the

\footnotetext{
is Assuming that the specific heat and specific volume are linear functions of the temperature, and also assuming that the volume of the calorimeter is the same as for equilibrium conditions, the indicated temperature would be identical with the mean effective temperature, $\theta$, as defined on page 404 . These assumptions are all so nearly true for the conditions of the experiments that the difference between the two temperatures is insignificant.
} 
calorimeter, whether in equilibrium or not, provided this temperature be defined as above; that is, as the effective mean temperature of the contents or the equivalent equilibrium temperature. The calibration was found to be very nearly linear.

These experiments were carried out at various temperatures and pressures in the range of the specific heat determinations and also at various rates of heating. The jacket was kept as nearly as possible at the same temperature as the calorimeter, just as in the specific heat determinations.

The results of a single experiment are shown graphically in Fig. 3. The temperatures are all plotted with respect to time. The mean temperature, $\theta$, of the calorimeter contents is shown by curve $\mathrm{I}$. The ideal temperature, supposing the heat added at a uniform rate to be instantaneously distributed, is shown by the dotted line, which is very nearly straight. The jacket temperature is shown by curve 2. This curve also represents the average temperature of the calorimeter surface, since the temperatures of these two surfaces were kept very closely together. The temperatures of the points $A, B$, and $C$ are shown by curves 5,3 , and 4 . (The points $A$ and $B$ were found to have always essentially the same temperature during the period of heating, and hence curves 5 and 3 coincide for this period.) These curves were plotted by reference to curve 2 , using the reduced thermocouple readings.

By study of these curves the temperature changes may be readily analyzed. Initially all parts of the system are at the same temperature, $\theta_{1}$. In a short time after starting the heating current, the rate of rise of the temperature $\theta$, as indicated by the outflow, has become constant and remains so until the interruption of the heating current, after which the outflow almost immediately ceases and a slight recession of the liquid gradually occurs while equilibrium is being reestablished. The calorimeter top and the observed points of the outflow tube are more remote from the source of heat, and the temperatures at these points therefore lag behind $\theta$. After a few minutes, during which the convection currents are being established, this lag becomes nearly constant and remains so during the addition of heat. The manner in which the various parts resume equilibrium is shown in the portion beyond the vertical dotted line which marks the time of interruption of the current. The example given is characteristic of what was observed in each of the entire series of experiments.

For the purpose of evaluating the deficiency of heat in the outflow below what it would have contained were there no lag, 


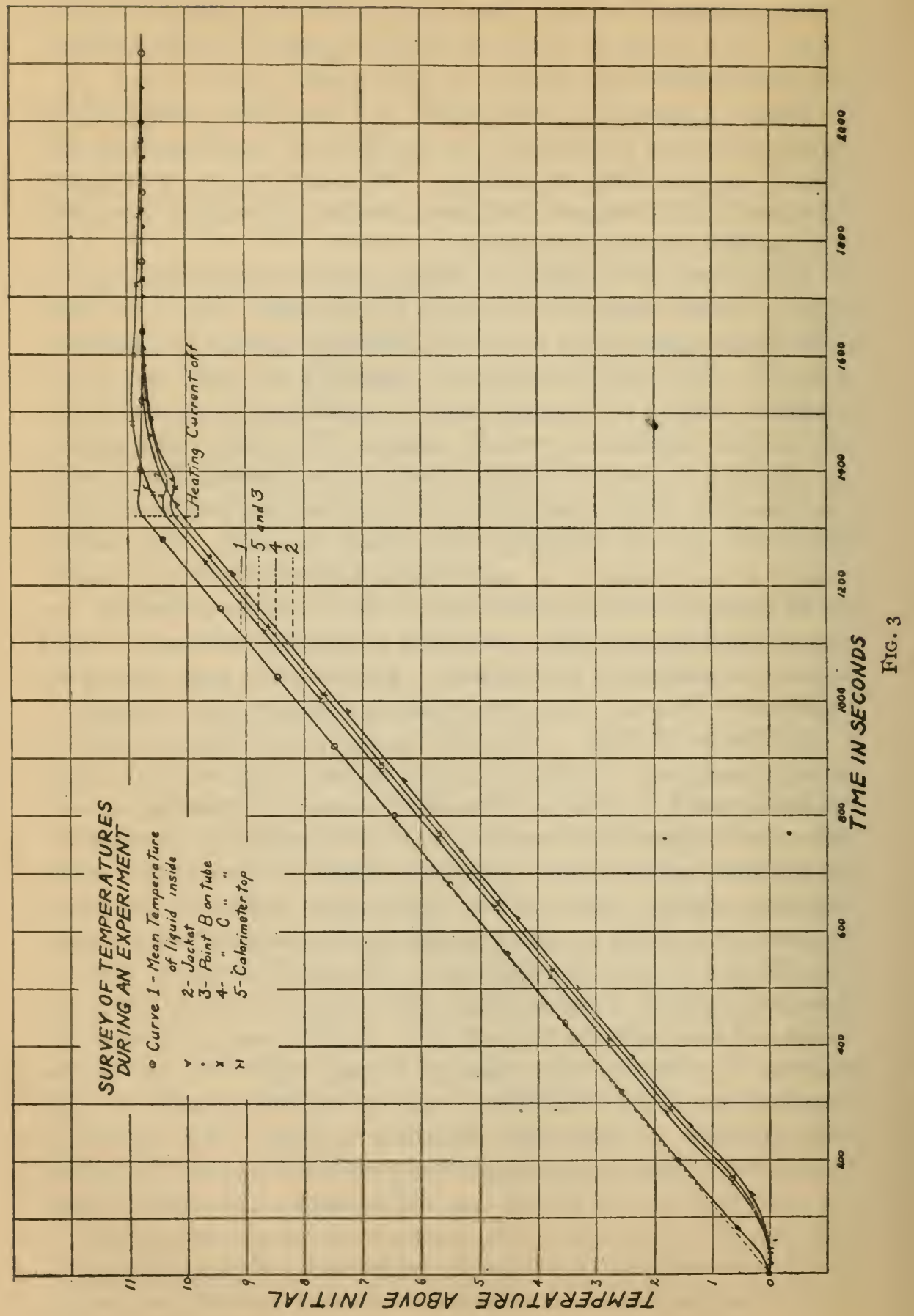


a sufficiently accurate, simple statement of the results is possible if two periods are considered, the first relatively short, in which the outflow temperature $\theta^{\prime}$ is assumed to remain equal to the initial temperature $\theta_{1}$, and a second, lasting until $\theta_{2}$ is reached at the end of the outflow, in which $\theta-\theta^{\prime}$ remains nearly constant. Accordingly, using symbols

$$
\begin{aligned}
\text { for } \quad \theta_{1} & <\theta=\theta_{1}+\lambda, & \theta^{\prime} & =\theta_{1} \\
\text { for } \theta_{1}+\lambda & <\theta \quad \overline{>}_{\theta}, & \theta^{\prime} & =\theta-\lambda
\end{aligned}
$$

The value of $\lambda$ was found to depend only slightly on the rate of heating. For the rate of $0.5^{\circ}$ per minute, within the range of temperature $-40^{\circ}$ to $+40^{\circ} \mathrm{C}$., i. e., for the conditions under which the determinations of $C_{p}$ were made, $\lambda$ in degrees as determined in the supplementary experiments may be expressed by the equation:

$$
\lambda=0.53-0.0028 \theta
$$

It is readily seen that in any of the determinations of $C_{p}$, each of which was for a temperature interval of about ro degrees, the change in $\lambda$ is less than $0{ }^{\circ} \mathrm{o} 3$, and therefore in any experiment, $\lambda$, which enters as a factor in a small correction term, can be regarded as constant.

\section{RESULTS OF MEASUREMENTS}

The experimental data obtained from the observations for the determinations of the heat capacity of the liquid at constant pressure made by the second method are given in Table 4 , together with the computations for obtaining the heat added to the liquid per unit mass, at mean temperature per unit temperature change; i. e., $\frac{\mathrm{I}}{(M)_{m}} \frac{\Delta Q}{\Delta \theta^{\circ}}$ The computations were made following the method described in Section IV. 


\begin{tabular}{|c|c|}
\hline 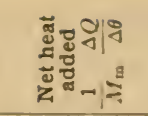 & 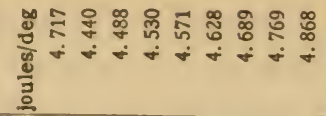 \\
\hline 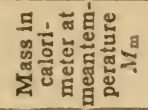 & 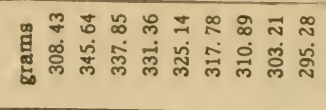 \\
\hline 选 & 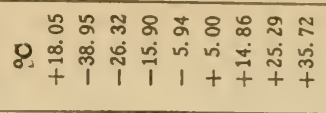 \\
\hline 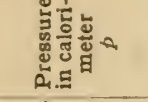 & 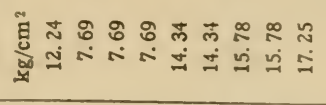 \\
\hline 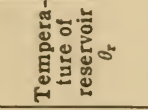 & 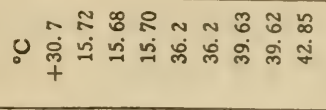 \\
\hline 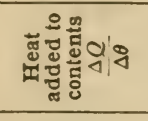 & 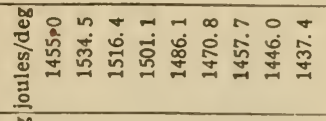 \\
\hline 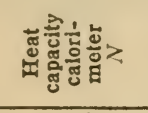 & 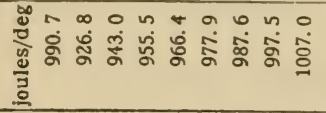 \\
\hline 送 & 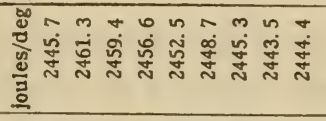 \\
\hline 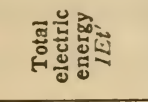 & 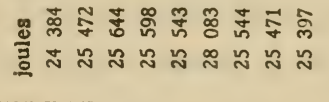 \\
\hline 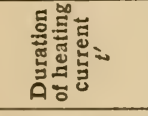 & 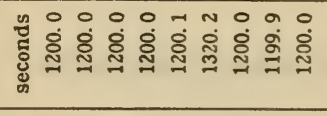 \\
\hline मिं & 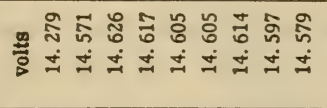 \\
\hline 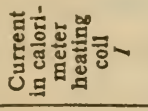 & 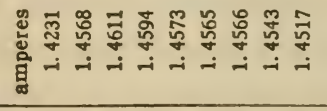 \\
\hline 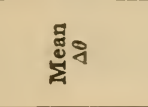 & 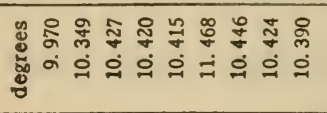 \\
\hline 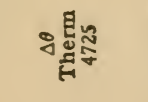 & 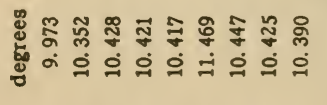 \\
\hline 㩆是 & 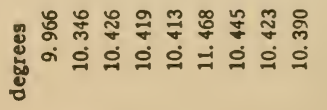 \\
\hline 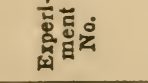 & nMTn \\
\hline A & $\begin{array}{l}\vec{\sim} \stackrel{\infty}{N} \\
\stackrel{a}{\Xi}\end{array}$ \\
\hline
\end{tabular}


The pressure, $p$, corresponding to saturated vapor pressures at temperatures, $\theta_{r}$, in the reservoir were obtained from data for pressure of saturated ammonia vapor given by Keyes and Brownlee. ${ }^{14}$

The data obtained from the observations for determining at various temperatures the mass contained in the calorimeter and the variations with pressure of the mass contained appear in Table 5 .

TABLE 5.-Method 2-Mass of Liquid in Calorimeter when Full at Saturation Pressure

\begin{tabular}{|c|c|c|c|c|c|c|c|}
\hline $\begin{array}{c}\text { Temper- } \\
\text { ature } \\
\theta\end{array}$ & $\begin{array}{l}\text { Mass } \\
\text { liquid } \\
\frac{\| 1}{N}\end{array}$ & $\begin{array}{l}\text { Change } \\
\text { of mass } \\
\text { with } \\
\text { temper- } \\
\text { ature } \\
\frac{\mathrm{d} M}{\mathrm{~d} \theta}\end{array}$ & $\begin{array}{c}\text { Change } \\
\text { of mass } \\
\text { with } \\
\text { pressure } \\
\left(\frac{\partial M}{\partial p}\right)_{\theta}\end{array}$ & $\begin{array}{c}\text { Temper- } \\
\text { ature } \\
\theta\end{array}$ & $\begin{array}{l}\text { Mass } \\
\text { liquid } \\
\underset{M}{\text { Mand }}\end{array}$ & $\begin{array}{l}\text { Change } \\
\text { of mass } \\
\text { with } \\
\text { temper- } \\
\text { ature } \\
\frac{\mathrm{d} M}{\mathrm{~d} \theta}\end{array}$ & $\begin{array}{c}\text { Change } \\
\text { of mass } \\
\text { with } \\
\text { pressure } \\
\left(\frac{\partial M}{\partial p}\right)_{\theta}\end{array}$ \\
\hline${ }^{\circ} \mathrm{C}$ & grams & $\frac{\text { grams }}{\text { deg. }}$ & $\frac{\text { grams }}{\mathrm{kg} / \mathrm{cm}^{2}}$ & ${ }^{\circ} \mathrm{C}$ & grams & $\frac{\text { grams }}{\text { deg. }}$ & $\frac{\text { grams }}{\mathrm{kg} / \mathrm{cm}^{2}}$ \\
\hline-50 & 352.0 & 0.60 & 0.033 & 10 & 313.8 & 0.69 & 0.046 \\
\hline-40 & 345.9 & .61 & .034 & 20 & 306.7 & .72 & .052 \\
\hline-30 & 339.8 & .62 & .035 & 30 & 299.3 & .76 & .059 \\
\hline-20 & 333.6 & .63 & .036 & 40 & 291.5 & .80 & .069 \\
\hline-10 & 327.3 & .65 & .038 & 50 & 283.2 & .86 & .080 \\
\hline 0 & 320.7 & .67 & .041 & & & & \\
\hline
\end{tabular}

The computation of the values of $C_{p}$ at pressures above saturation is found in Table 6 , the correction for heat to expelled liquid being computed, using for $\lambda$ equation ( 16 ).

The further computation of the limiting value of $C_{p}$ at pressure $\pi$, corresponding to saturation at temperature $\theta_{m}$, follows in Table 6 , for this computation the coefficient $\theta \frac{\partial}{\partial \theta}\left(\frac{l}{\theta}\right)$, obtained from independent measurements of the latent heat of pressure variation and published elsewhere, ${ }^{15}$ being used.

14 Thermodynamic Properties of Ammonia, p. 13, John Wiley \& Son; 19r6.

15 To appear in this Bulletin. 
TABLE 6.-Method 2-Calculation of Specific Heat at Constant Pressure Equal to Saturation Pressure

\begin{tabular}{|c|c|c|c|c|c|c|c|c|c|c|c|}
\hline $\begin{array}{c}\text { Heat } \\
\text { added to } \\
\text { liquid } \\
\frac{1}{M_{m}} \frac{\Delta Q}{\Delta \theta}\end{array}$ & $\begin{array}{c}\text { Mean } \\
\text { temp. } \\
\theta_{m}\end{array}$ & $\begin{array}{c}\text { Corr. } \\
\text { for } \\
\text { heat } \\
\text { to ex- } \\
\text { pelled } \\
\text { liquid } \\
\frac{1}{M_{m}} C_{p} \lambda \\
\times \frac{\Delta M}{\Delta \theta}\end{array}$ & $\begin{array}{c}\text { Spe- } \\
\text { cific } \\
\text { heat at } \\
\text { press. } p \\
\text { temp. } \theta_{m} \\
C_{p}\end{array}$ & $\begin{array}{c}\text { Pres- } \\
\text { sure } \\
p\end{array}$ & $\begin{array}{c}\text { Satu- } \\
\text { ration } \\
\text { pres- } \\
\text { Sure } \\
\text { at } \theta_{m} \\
\pi\end{array}$ & $p-\pi$ & $\begin{array}{c}\text { Change } \\
\text { in } C_{p} \\
\text { with } \\
\text { pressure } \\
{ }_{\theta}^{\partial} \frac{\partial}{\partial \theta}\left(\frac{l}{\theta}\right)\end{array}$ & $\overbrace{\substack{10 \\
010 \\
0 \\
k \\
5}}^{k}$ & $\begin{array}{c}\text { Spe- } \\
\text { cific } \\
\text { heat at } \\
\text { const. } \\
\text { press. } \\
\text { equal } \\
\text { to satu- } \\
\text { ration } \\
\text { press. } \\
\left.C_{p}\right]_{0, \pi}\end{array}$ & $\begin{array}{c}C \pi \\
\text { Calc. }\end{array}$ & $\begin{array}{l}\text { Obs.- } \\
\text { Calc. }\end{array}$ \\
\hline $\begin{array}{r}\mathrm{J} / \mathrm{g} . \mathrm{deg} \\
4.440\end{array}$ & $\begin{array}{c}{ }^{\circ} \mathrm{C} \\
-38.95\end{array}$ & $\begin{array}{l}\mathrm{J} / \mathrm{g} . \mathrm{deg} \\
+0.005\end{array}$ & $\begin{array}{c}\mathrm{J} / \mathrm{g} . \mathrm{deg} \\
4.445\end{array}$ & $\begin{array}{r}\mathrm{kg} / \mathrm{cm}^{2} \\
7.69\end{array}$ & $\begin{array}{c}\mathrm{kg} / \mathrm{cm}^{2} \\
0.77\end{array}$ & $\begin{array}{r}\mathrm{kg} \mathrm{cm}^{2} \\
6.92\end{array}$ & 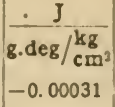 & $\begin{array}{l}\mathrm{J} / \mathrm{g} . \mathrm{deg} \\
-0.002\end{array}$ & $\begin{array}{c}\mathrm{J} / \mathrm{g} . \mathrm{deg} \\
4.447\end{array}$ & $\begin{array}{r}J / 8 . d e g \\
4.450\end{array}$ & $\begin{array}{c}\mathrm{J} / \mathrm{g} . \mathrm{deg} \\
-0.003\end{array}$ \\
\hline 4.488 & -26.32 & +.005 & 4. 493 & 7.69 & 1.26 & 6.43 & .00041 & .003 & 4.496 & 4.494 & +.002 \\
\hline 4. 530 & -15.90 & +.005 & 4. 535 & 7.69 & 2.32 & 5.37 & .00052 & .003 & 4. 538 & 4. 536 & +.002 \\
\hline 4.571 & -5.94 & +.005 & 4.576 & 14.34 & 3.53 & 10.81 & .00064 & .007 & 4.583 & 4. 582 & +.001 \\
\hline 4. 628 & +5.00 & +.005 & 4. 633 & 14. 34 & 5.29 & 9.05 & .00079 & .007 & 4. 640 & 4. 641 & -.001 \\
\hline 4. 689 & +14.86 & +.005 & 4. 694 & 15. 78 & 7.44 & 8.34 & .00099 & .008 & 4. 702 & 4. 703 & -.001 \\
\hline 4. 717 & +18.05 & +.005 & 4. 722 & 12. 24 & 8. 28 & 3. 96 & .00105 & .004 & 4. 726 & 4. 726 & \pm .000 \\
\hline 4. 769 & +25.29 & +.005 & 4. 774 & 15.78 & 10.41 & 5.37 & .00123 & .006 & 4.780 & 4. 782 & -.002 \\
\hline 4.868 & +35.72 & +.006 & 4.874 & 17.25 & 14.14 & 3. 11 & .00157 & .005 & 4.879 & 4.877 & +.002 \\
\hline
\end{tabular}

This limiting value of $C_{p}$ may be represented by the empirical equation:

$$
\left.C_{p}\right]_{\theta, \pi}=3.8927+\frac{95 \cdot 779}{133-\theta}
$$

Values of $C_{p}$ computed by means of this equation and comparison of these computed with the observed values are given in the same table.

In Table 7 the computation of the specific heat of the saturated liquid from the limiting values of $C_{p}$ corresponding to saturation is made, using the limiting values of $l$ obtained from the independent measurements mentioned above.

The values of the specific heat, $\sigma$, of the saturated liquid computed from the measurements made at constant pressure may be represented by the empirical equation:

$$
\sigma=3.1800-0.00050 \theta+\frac{16.356}{\sqrt{133-\theta}}
$$

A comparison between the values of $\sigma$ computed by this equation and those actually determined is given in the same table. 
TARLE 7.-Method 2-Caiculation of Specific Heat of Saturated Liquid Ammonia

\begin{tabular}{|c|c|c|c|c|c|}
\hline $\begin{array}{c}\text { Temp. } \\
\theta\end{array}$ & $\begin{array}{c}\text { Specific } \\
\text { heat at } \\
\text { const. } \\
\text { press. }\end{array}$ & $\begin{array}{c}\text { Heat of } \\
\text { pressure } \\
\text { variation } \\
\left.C_{p}\right]_{\theta, \pi}\end{array}$ & $\begin{array}{c}\text { Specific } \\
\text { heat at } \\
\text { satura- } \\
\text { tion } \\
\sigma \theta\end{array}$ & $\begin{array}{c}\text { Specific } \\
\text { heat } \\
\text { calc. by } \\
\text { equation } \\
(B) \\
\sigma_{c a l c .}\end{array}$ & $\begin{array}{c}\text { Obs- } \\
\text { calc }\end{array}$ \\
\hline${ }^{\circ} \mathrm{C}$ & $\mathrm{J} / \mathrm{g} . \operatorname{deg}$ & $\mathrm{J} / \mathrm{g} . \mathrm{deg}$ & $\mathrm{J} / \mathrm{g} . \mathrm{deg}$ & $\mathrm{J} / \mathrm{g} \cdot \mathrm{deg}$ & $\mathrm{J} / \mathrm{g} . \mathrm{deg}$ \\
-38.95 & 4.447 & -0.002 & 4.445 & 4.447 & -0.002 \\
-26.32 & 4.495 & .005 & 4.491 & 4.489 & +.002 \\
-15.90 & 4.538 & .008 & 4.530 & 4.529 & +.001 \\
-5.94 & 4.583 & .012 & 4.571 & 4.571 & \pm .000 \\
+5.00 & 4.640 & .018 & 4.622 & 4.623 & -.001 \\
14.86 & 4.702 & .026 & 4.676 & 4.678 & -.002 \\
18.05 & 4.726 & .029 & 4.697 & 4.697 & \pm .000 \\
25.29 & 4.780 & .038 & 4.742 & 4.743 & -.001 \\
35.72 & 4.879 & .055 & 4.824 & 4.821 & +.003 \\
\hline
\end{tabular}

\section{FORM OF EMPIRICAL EQUATION FOR SPECIFIC HEAT OF THE SATURATED LIQUID}

A form of empirical equation was sought which would closely fit the experimental data and which would also be consistent with other known physical facts. Keyes and Brownlee ${ }^{16}$ have given an empirical equation for the specific heat of saturated liquid ammonia, the form of which they chose because "it seems probable that the heat capacity becomes infinite at the critical temperature." This conclusion appears as certain as any physical fact well can be which is not susceptible of direct experimental proof. It is, however, not of more importance than the manner of variation by which the infinite value is reached, and if used alone may easily lead to a form of empirical equation which gives the absurd result of an infinite value for the heat content of the liquid at the critical point. Therefore the limitation should also be imposed that the heat added for any finite temperature increment must be finite.

An empirical equation for $\sigma$ over an extended range should, therefore, conform to two criteria in addition to adaptability to the experimental data, namely,

$$
\begin{aligned}
& \sigma_{c}=\infty \\
& \int_{0}^{\theta_{c}} \sigma d \theta \neq \infty
\end{aligned}
$$

where $\theta_{c}$ is the temperature of the critical point. 
An equation of the form $\sigma=A+B \theta+\frac{C}{\left(\theta_{c}-\theta\right)^{1 / 2}}$ has been found to meet these requirements, and has been used to represent the results of the present investigation. The equation has the further advantage of giving no real values above the critical temperature.

The form of equation used by Keyes and Brownlee ${ }^{17}$ was found to be unsuited to represent these results; indeed, when applied to the data here given the constants found were such as to give a maximum for $\sigma$ at about $100^{\circ}$ and $-\infty$ at the critical temperature $133^{\circ}$.

\section{CONCLUSIONS}

3

The results of the determinations by the two independent methods have been expressed by the following two empirical equations:

First method: $\quad \sigma=3.0931-0.00064 \theta+\frac{17.329}{\sqrt{133-\theta}}$

Second method: $\sigma=3.1800-0.00050 \theta+\frac{16.356}{\sqrt{133-\theta}}$

where the positive value of the square root is to be used.

The agreement of the results by the two methods is shown by the following values computed from the equations:

\begin{tabular}{|c|c|c|c|c|c|}
\hline Temperature .............. & $-40^{\circ}$ & $-20^{\circ}$ & $0^{\circ}$ & $20^{\circ}$ & $40^{\circ}$ \\
\hline Equation (A)... & 4.438 & 4. 508 & 4. 599 & 4.711 & 4. 864 \\
\hline Equation (B).. & 4. 444 & 4. 513 & 4. 599 & 4.710 & 4.856 \\
\hline Mean.. & 4.441 & 4. 510 & 4.539 & 4.710 & 4. 860 \\
\hline
\end{tabular}

The greatest difference between the mean results by both methods and the results of either method as represented by empirical equations is seen to be less than I part in rooo.

In Fig. 4 the results of all the determinations by both methods are shown graphically.

In Table 8 the average and maximum deviations of individua. experiments from mean values are assembled for convenience in comparison. 


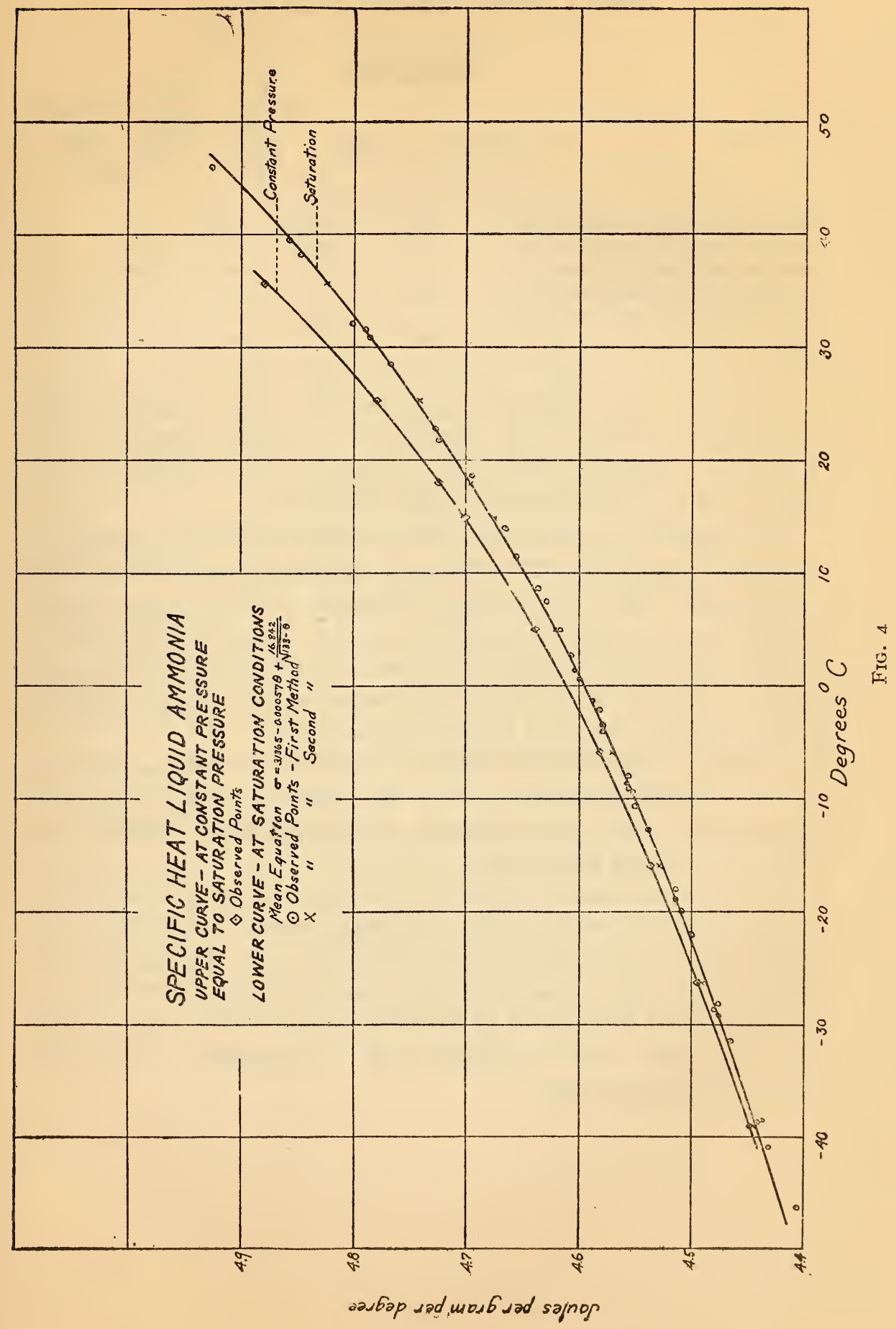


TABLE 8.-Analysis of Precision-Both Methods

\begin{tabular}{|c|c|c|c|c|c|}
\hline \multirow{2}{*}{ Comparison } & \multicolumn{2}{|c|}{$\begin{array}{l}\text { Mean deviation- } \\
\text { parts per } 10000\end{array}$} & \multirow{2}{*}{$\begin{array}{l}\text { Per cent } \\
\text { of } \\
\text { number } \\
\text { of obser- } \\
\text { vations } \\
\text { within } \\
1 \text { part per } \\
1000\end{array}$} & \multirow{2}{*}{$\begin{array}{c}\text { Per cent } \\
\text { of } \\
\text { number } \\
\text { within } 2 \\
\text { parts per } \\
1000\end{array}$} & \multirow{2}{*}{$\begin{array}{l}\text { Maximum } \\
\text { deviation } \\
\text { parts per } \\
10000\end{array}$} \\
\hline & $\begin{array}{l}\text { Above } \\
0^{\circ} .0 \mathrm{C}\end{array}$ & $\begin{array}{l}\text { Below } \\
0^{\circ} .0 \mathrm{C}\end{array}$ & & & \\
\hline$\sigma(\operatorname{method} 1)$ with empirical equation (A).. & \pm 6 & \pm 6 & 90 & 98 & 27 \\
\hline - (method 2) with empirical equation (B)... & \pm 3 & \pm 3 & 100 & 100 & 6 \\
\hline$\sigma(\operatorname{method} 1)$ with empirical equation (C)... & \pm 7 & \pm 7 & 81 & 98 & 36 \\
\hline $\begin{array}{l}\sigma \text { (method 2) with empirical equation (C)... } \\
\sigma \text { (both methods) with empirical equation }\end{array}$ & \pm 3 & \pm 7 & 100 & 100 & 10 \\
\hline 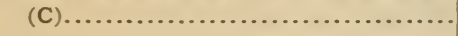 & \pm 6 & \pm 7 & 84 & 96 & 36 \\
\hline
\end{tabular}

In Table 9, by assigning to the elements which enter into the determination of the result, $\sigma$, estimated values of the average and maximum accidental errors, the corresponding accidental errors which would be produced in $\sigma$ were estimated.

For method I, comparison of the calculated with the observed deviations shows that the maximum deviations observed were to be expected, while the average deviations observed were slightly larger than were expected, unless they are to be explained by reason of distillation in the connecting tubes. If an average deviation of about 6 parts in ro ooo due to this cause were assumed, it would account for the observed average deviation.

A similar comparison for method 2 showed excellent agreement for the average deviations, while the observed maximum deviation was less than that estimated, as it might likely happen in so limited a series of observations.

A similar calculation applied to the total errors enables limits to be established within which the actual errors should be. As a result of this calculation it is found that total errors to be expected should not exceed 6 parts in 10000 and the extreme total error possible should not exceed 55 parts in ro 000 . These figures agree very well with those obtained from a comparison of the two methods with the mean. 


\section{TABLE 9.-Estimation of Errors}

[All errors are parts in to 000 produced in the final result $\sigma$ ]

\begin{tabular}{|c|c|c|c|c|c|c|c|c|c|c|}
\hline \multirow{3}{*}{$\begin{array}{l}\text { Source of error. } \\
\text { Quantity measured } \\
\text { or calculated }\end{array}$} & \multicolumn{4}{|c|}{ First method } & \multicolumn{4}{|c|}{ Second method } & \multirow{2}{*}{\multicolumn{2}{|c|}{$\begin{array}{l}\text { Both } \\
\text { methods. } \\
\text { Total errors }\end{array}$}} \\
\hline & \multicolumn{2}{|c|}{$\begin{array}{l}\text { Fortuitous } \\
\text { errors }\end{array}$} & \multicolumn{2}{|c|}{ Total errors } & \multicolumn{2}{|c|}{$\begin{array}{c}\text { Fortuitous } \\
\text { errors }\end{array}$} & \multicolumn{2}{|c|}{ Total errors } & & \\
\hline & $\begin{array}{l}\text { Aver- } \\
\text { age }\end{array}$ & $\begin{array}{l}\text { Pos- } \\
\text { sible }\end{array}$ & $\begin{array}{l}\text { Aver- } \\
\text { age }\end{array}$ & $\begin{array}{l}\text { Pos- } \\
\text { sible }\end{array}$ & $\begin{array}{l}\text { Aver- } \\
\text { age }\end{array}$ & $\begin{array}{l}\text { Pos- } \\
\text { sible }\end{array}$ & $\begin{array}{l}\text { Aver- } \\
\text { age }\end{array}$ & $\begin{array}{l}\text { Pos- } \\
\text { sible }\end{array}$ & $\begin{array}{l}\text { Aver- } \\
\text { age }\end{array}$ & $\begin{array}{l}\text { Pos- } \\
\text { sible }\end{array}$ \\
\hline Measurement of & & & & & & & & & & \\
\hline energy............. & \pm 4 & \pm 8 & \pm 4 & \pm 8 & \pm 4 & \pm 8 & \pm 4 & \pm 8 & \pm 4 & \pm 8 \\
\hline $\begin{array}{r}\text { Measureme } n t \text { of } \\
\text { temperatu re } \\
\text { change........... }\end{array}$ & . 2 & 10 & 2 & 10 & 2 & 10 & 2 & 10 & 2 & \\
\hline Thermal leakage.... & 1 & 5 & 1 & 5 & 1 & 5 & 1 & 5 & 1 & 20 \\
\hline $\begin{array}{l}\text { Corre } \mathrm{t} \text { i o n f or } \\
\text { change of phase in- } \\
\text { side closed calor- } \\
\text { imeter ............. }\end{array}$ & 0 & 2 & 6 & 10 & & & & & 6 & \\
\hline $\begin{array}{l}\text { Heat capacity calor- } \\
\text { imeter } . . . . . . . . .\end{array}$ & 0 & 1 & 3 & 5 & 0 & 1 & 3 & 5 & 3 & \\
\hline $\begin{array}{l}\text { Determina tion of } \\
\text { mass in calorim- } \\
\text { eter................ }\end{array}$ & 0 & 0 & 0 & 0 & 0 & 2 & 2 & 4 & 2 & \\
\hline $\begin{array}{l}\text { Correction for heat } \\
\text { of pressure varia- } \\
\text { tion................ }\end{array}$ & & & & & 0 & 2 & 2 & 10 & 3 & \\
\hline $\begin{array}{l}\text { Correction for lag of } \\
\text { outgoing } 1 \mathrm{i} \mathrm{q} \mathrm{u} \mathrm{i} \mathrm{d} \\
\text { (second method).. }\end{array}$ & & & & & 0 & 2 & 2 & 3 & 2 & \\
\hline $\begin{array}{l}\text { Total, calcu- } \\
\text { lated from } \\
\text { above esti- } \\
\text { mations..... }\end{array}$ & \pm 4 & \pm 26 & \pm 6 & \pm 38 & \pm 4 & \pm 30 & \pm 4 & \pm 45 & \pm 6 & \pm 55 \\
\hline $\begin{array}{r}\text { Total, by com- } \\
\text { paris on of } \\
\text { observed } \\
\text { points with } \\
\text { least square } \\
\text { reductions... }\end{array}$ & \pm 6 & \pm 27 & \pm 7 & \pm 36 & \pm 3 & \pm 6 & \pm 5 & \pm 10 & \pm 7 & \pm 36 \\
\hline
\end{tabular}


The order of accuracy of the two methods seems to be about the same, with a slight advantage in favor of the second. Giving each method equal weight, the final mean value of $\sigma$ in joules per gram per degree is expressed in the range $-45^{\circ}$ to $+45^{\circ} \mathrm{C}$ by the equation:

$$
\sigma=3.1365-0.00057 \theta+\frac{16.8+2}{\sqrt{1} 33-\theta}
$$

If the relation between the joule and the $20^{\circ}$ calorie ${ }^{18}$ be taken as I calorie ${ }_{20}=4.183$ joules, the specific heat, $\sigma$, in $\mathrm{Cal}_{20} / \mathrm{g}$. deg., of liquid ammonia under saturation conditions is given by the equation:

$$
\sigma=0.7498-0.000136 \theta+\frac{4.0263}{\sqrt{133-\theta}}
$$

\section{SUMMARY}

Using a calorimeter of the aneroid type specially designed for the peculiar conditions, the specific heat of saturated liquid ammonia has been determined throughout the temperature interval $-45^{\circ}$ to $+45^{\circ} \mathrm{C}$.

A brief description of the instrument is given in this paper. A detailed description of the design and construction are given in a separate paper.

Two distinct and independent methods were used, each of which avoids sources of error present in the other. In the first method the heat added to a fixed amount confined in the calorimeter under saturation conditions and the resulting change in temperature are measured. By using data for the specific volumes of the two phases and the latent heat of vaporization, the corrections for the vapor are applied, giving the specific heat of the liquid kept saturated.

In the second method the calorimeter is kept full of liquid at a constant pressure. The heat added to the variable amount in the calorimeter and the resulting change in temperature are measured. A correction for the heat withdrawn in the expelled liquid is determined by special experiments. By use of the data for the latent heat of pressure variation of the liquid, obtained from separate measurements, made with the same apparatus and material, the corrections for pressure variation are applied, the result being to give a second determination of the specific heat of the saturated liquid.

13 The $20^{\circ}$ calorie is taken as the quantity of heat per gram (mass) per degree centigrade required to raise the temperature of water at $20^{\circ} \mathrm{C}$. at normal atmospheric pressure. 
The greatest difference between the mean results of both methods and the results of either method as represented by empirical equations is less than I part in rooo.

As a final result, the specific heat $\sigma$, in joules per gram per degree centigrade, of liquid ammonia, kept saturated, at the temperature $\theta$, is given in the range $-45^{\circ}$ to $+45^{\circ} \mathrm{C}$ by the equation

$$
\sigma=3.1365-0.00057 \theta+\frac{16.842}{\sqrt{133-\theta}}
$$

WASHINGTON, February ro, r9r 7 . 


\section{APPENDIX}

TABLE 10.- Specific Heat of Liquid Ammonia Under Saturation Conditions

[Expressed in Caloriesso per Gram per Degree C]

\begin{tabular}{|c|c|c|c|c|c|c|c|c|c|c|}
\hline Temp. ${ }^{\circ} \mathrm{C}$ & 0 & 1 & 2 & 3 & 4 & 5 & 6 & 7 & 8 & 9 \\
\hline-40 & 1.062 & 1.061 & 1.060 & 1.059 & 1.058 & 1.058 & 1.057 & 1.056 & 1.055 & 1.055 \\
\hline-30 & 1.070 & 1.069 & 1.058 & 1.067 & 1.056 & 1.055 & 1.064 & 1. 064 & 1.063 & 1.062 \\
\hline-20 & 1.078 & 1.077 & 1.076 & 1.075 & 1.074 & 1.074 & 1.073 & 1.072 & 1.071 & 1.070 \\
\hline-10 & 1.088 & 1.087 & 1.085 & 1.085 & 1.084 & 1.083 & 1.082 & 1.081 & 1.080 & 1.079 \\
\hline-0 & 1.099 & 1.098 & 1.097 & 1.096 & 1.091 & 1.093 & 1.092 & 1.091 & 1.090 & 1.089 \\
\hline+0 & 1.099 & 1.100 & 1.101 & 1.103 & 1. 104 & 1. 105 & 1.106 & 1. 108 & 1.109 & 1.110 \\
\hline+10 & 1.112 & 1.113 & 1.114 & 1.116 & 1. 117 & 1.118 & 1.120 & 1. 122 & 1.123 & 1.125 \\
\hline+20 & 1.126 & 1.128 & 1.129 & 1. 131 & 1.132 & 1.134 & 1.136 & 1.137 & i. 139 & 1. 141 \\
\hline+30 & 1. 142 & 1. 144 & 1.146 & 1.148 & 1. 150 & 1.152 & 1.154 & 1.156 & 1.158 & 1.160 \\
\hline+40 & 1.162 & 1.164 & 1.166 & 1.169 & 1.171 & 1.173 & 1.176 & 1.178 & 1. $18 !$ & 1.183 \\
\hline
\end{tabular}

TABLE 11.-Heat Content of Saturated Liquid Ammonia ${ }^{19}$

[Reckoned from the temperature of melting ice]

CALORIES PER GRAM

\begin{tabular}{|c|c|c|c|c|c|c|c|c|c|c|}
\hline Temp., ${ }^{\circ} \mathrm{C}$ & 0 & 1 & 2 & 3 & 4 & 5 & 6 & 7 & 8 & 9 \\
\hline-40 & -43.3 & -44.3 & -45.4 & -46.4 & -47.5 & -48.6 & -49.6 & -50.7 & -51.7 & -52.8 \\
\hline-30 & 32.6 & 33.6 & 34.7 & 35.8 & 36.8 & 37.9 & 39.0 & 40.0 & 41.1 & 42.2 \\
\hline-20 & 21.8 & 22.9 & 24.0 & 25.1 & 26.2 & 27.2 & 28.3 & 29.3 & 30.4 & 31.5 \\
\hline-10 & 11.0 & 12.1 & 13.1 & 14.2 & 15.3 & 16.4 & 17.5 & 19.6 & 19.7 & 25.8 \\
\hline-0 & 0.0 & 1.0 & 2.2 & 3.3 & 4.4 & 5.5 & 6.6 & 7.7 & 8.8 & 9.9 \\
\hline+0 & +0.0 & +1.1 & +2.2 & +3.3 & +4.4 & +5.5 & +6.7 & +7.8 & +8.9 & +10.0 \\
\hline+10 & 11.1 & 12.2 & 13.4 & 14.5 & 15.6 & 16.7 & 17.9 & 19.0 & 20.1 & 21.3 \\
\hline+20 & 22.4 & 23.5 & 24.7 & 25.8 & 27.0 & 28.1 & 29.3 & 33.4 & 31.6 & 32.7 \\
\hline+30 & 33.9 & 35.0 & 36.2 & 37.4 & 38.5 & 39.7 & 40.8 & 42.0 & 43.2 & 44.4 \\
\hline+40 & 45.5 & 46.7 & 47.9 & 49.1 & 50.3 & 51.5 & 52.7 & 53.8 & 55.0 & 56.2 \\
\hline
\end{tabular}

BTU PER POUND

\begin{tabular}{|c|c|c|c|c|c|c|c|c|c|c|}
\hline Temp., ${ }^{\circ} \mathrm{F}$ & 0 & 1 & 2 & 3 & 4 & 5 & 6 & 7 & 8 & 9 \\
\hline-40 & -77.9 & -78.9 & -80.0 & -81.1 & -82.1 & -83.2 & -84.3 & -85.3 & -86.4 & -87.4 \\
\hline-30 & 67.2 & 68.3 & 69.4 & 70.4 & 71.5 & 72.6 & 73.6 & 74.7 & 75.8 & 76.8 \\
\hline-20 & 56.5 & 57.6 & 58.7 & 59.8 & 60.8 & 61.9 & 63.0 & 64.0 & 65.1 & 66.2 \\
\hline-10 & 45.8 & 46.9 & 48.0 & 49.0 & 50.1 & 51.2 & 52.3 & 53.3 & 54.4 & 55.5 \\
\hline-0 & 35.0 & 36.1 & 37.2 & 38.2 & 39.3 & 40.4 & 41.5 & 42.6 & 43.6 & 44.7 \\
\hline+0 & 35.0 & 33.9 & 32.8 & 31.7 & 30.7 & 29.6 & 28.5 & 27.4 & 26.3 & 25.2 \\
\hline+10 & 24.1 & 23.0 & 21.9 & 20.9 & 19.8 & 18.7 & 17.6 & 16.5 & 15.4 & 14.3 \\
\hline+20 & 13.2 & 12.1 & 11.0 & 9.9 & 8.3 & 7.7 & 6.6 & 5.5 & 4.4 & 3.3 \\
\hline+30 & -2.2 & -1.1 & 0.0 & +1.1 & +2.2 & +3.3 & +4.4 & +5.5 & +6.7 & +7.8 \\
\hline+40 & +8.9 & +10.0 & +11.1 & 12.2 & 13.3 & 14.4 & 15.6 & 16.7 & 17.8 & 18.9 \\
\hline+50 & 20.0 & 21.1 & 22.3 & 23.4 & 24.5 & 25.6 & 26.8 & 27.9 & 29.0 & 30.1 \\
\hline+60 & 31.3 & 32.4 & 33.5 & 34.7 & 35.8 & 36.9 & 38.1 & 39.2 & 40.3 & 41.5 \\
\hline+70 & 42.6 & 43.8 & 44.9 & 4.6 .0 & 47.2 & 48.3 & 49.5 & 50.6 & 51.8 & 52.9 \\
\hline+80 & 54.1 & 55.2 & 56.4 & 57.5 & 58.7 & 59.8 & 61.0 & 62.1 & 63.3 & 64.4 \\
\hline+90 & 65.6 & 65.8 & 67.9 & 69.1 & 70.3 & 71.4 & 72.6 & 73.8 & 74.9 & 76.1 \\
\hline+100 & 77.3 & 78.5 & 79.6 & 80.8 & 82.0 & 83.2 & 84.3 & 85.5 & 85.7 & 87.9 \\
\hline+110 & 89.1 & 90.3 & - $\quad 91.5$ & 92.6 & 93.9 & 95.1 & 96.3 & 97.5 & 98.7 & 93.9 \\
\hline
\end{tabular}

18 Heat content as used here is defined by the relation:

$$
H=\epsilon+p v
$$

Where $H=$ heat content, taken as zero at the temperature of melting ice, $\epsilon=$ internal 0 : "intrinsic" energy, and $H, \epsilon$, and $p v$ are all expressed in the same units. 